\title{
EMOTION AND CONSCIOUSNESS: ENDS OF A CONTINUUM ${ }^{1}$
}

\author{
Yuri I. Alexandrov \\ Institute of Psychology, Russian Academy of Sciences \\ Moscow \\ Mikko E. Sams \\ Helsinki University of Technology \\ Helsinki (Finland)
}

We suggest a united concept of consciousness and emotion, based on the systemic cognitive neuroscience perspective regarding organisms as active and goaldirected. We criticize the idea that consciousness and emotion are psychological phenomena having quite different neurophysiological mechanisms. We argue that both characterize a unified systemic organization of behavior, but at different levels. All systems act to achieve intended behavioral results in interaction with their environment. Differentiation of this interaction increases during individual development. Any behavioral act is a simultaneous realization of systems ranking from the least to the most differentiated. We argue that consciousness and emotion are dynamic systemic characteristics that are prominent at the most and least differentiated systemic levels, correspondingly. These levels are created during development. Our theory is based on both theoretical and empirical research and provides a solid framework for experimental work.

Keywords: cognition, brain, learning, development, neuron, system.

\section{Introduction}

Research on emotions has increased drastically in psychology, psychophysiology and cognitive neuroscience during the last decade. Emotion (E) is regarded to play a crucial role in most psychological processes, such as memory, perception and attention (Davidson, Cacioppo,

This work was supported by RFBR grant 05-06-80357, RFHR grant 05-06-06055a and by The Grants Council of the President of the Russian Federation of the Major Scientific Schools of Russia grant NSh-1989.2003.6 to Yu.I. Alexandrov, and by the Academy of Finland grant 44897 to the Center of Excellence of Computational Science and Engineering and grant 200521 to M. Sams.

1 This article was published earlier in Cognitive Brain Research, 2005, 25. P. 387-405. 
1992; Zajonc, McIntosh, 1992). On the other hand, the nature of the consciousness $(\mathrm{C})$ has for years been one of the main theoretical problems in psychology and neuroscience. Interestingly, after being separated for decades, E and C are now clearly finding each other. Many scholars, including ourselves, think that they actually form a united concept and should be studied together (see, e.g., (Alexandrov, Yu.I., 1995; 1999a; 1999b; Damasio, 1994; 2000; Ellis, 1999; Ellis, Newton, 2000; LeDoux, 2000; McNaughton, 1997; Panksepp, 2000; Rolls, 1999)). We suggest that $\mathrm{C}$ and $\mathrm{E}$ actually characterize a single entity. In this paper, we discuss only those aspects of the $\mathrm{C}$ and $\mathrm{E}$ that are necessary to introduce the essence of our concept. The emphasis is on $\mathrm{E}$, while $\mathrm{C}$ has been discussed in more detail earlier (Alexandrov, Yu.I., 1999a; 1999b). Before going into the details, we first describe our general understanding of the relationship between $\mathrm{E}$ and $\mathrm{C}$.

Processes and mechanisms of $\mathrm{E}$ and $\mathrm{C}$ are typically assumed to be very different, even polar. Their unity is mostly seen as an interaction of two quite separate phenomena in the same machine (for additional criticism see (Brushlinskij, 2002; Rubinshtein, 1989)). One important reason for such thinking is emphasizing opposing pairs like "normal" vs. "pathological" and "cognitive" vs. "affective". Lewin suggested that such disjunctive thinking should be replaced by a perspective allowing transitional stages and gradual changes (Lewin, 1935). Another reason for viewing $\mathrm{E}$ and $\mathrm{C}$ as separate entities concerns the overestimation of the differences between organization levels in organism's processes. Such differences are real, but common systemic principles should also be taken into account (Anokhin, P.K., 1973; 1978).

The united concept of $\mathrm{C}$ and $\mathrm{E}$, based on the principle of continuity (Brushlinskij, 2002; Lewin, 1935) and the theory of functional systems (Anokhin, P.K., 1973) has been formulated within the theoretical framework of Fsystemic psychophysiology' (Alexandrov, Yu.I, 1995; 1999a; 1999 b), a term which is close to systemic cognitive neuroscience (Engel, Fries, Singer, 2001; Milner, Squire, Kandel, 1998). This concept takes into account common organizational principles valid at all systemic levels but also the cardinal differences between the levels.

In the present article, we will: (1) outline the essence of the united concept of $\mathrm{C}$ and $\mathrm{E}$, (2) sketch the main theoretical positions of systemic cognitive neuroscience, (3) describe the united concept in more details, (4) compare the united concept with others views, (5) provide empirical support for the united concept and (6) discuss the concept in relation to learning, ontogeny, phylogeny and action performance.

Our united concept of $\mathrm{C}$ and $\mathrm{E}$ regards organisms as active and goaldirected. We criticize the idea that $\mathrm{C}$ and $\mathrm{E}$ are psychological phenomena having quite different neurophysiological mechanisms. We argue that $\mathrm{C}$ and $\mathrm{E}$ both characterize a unified systemic organization of behavior, but at different levels. All systems act to achieve intended behavioral results in interaction with their environment. Differentiation of this interaction increases during individual development. Any behavioral act is a simultaneous realization of systems ranking from the least to the most differentiated. We argue that $\mathrm{C}$ and $\mathrm{E}$ are dynamic systemic characteristics that are prominent at the most and least differentiated systemic levels, respectively.

The notion of continuity in our concept means that there are no moments in development when $\mathrm{C}$ suddenly appears or E suddenly disappears. Each developmental and differentiation level is characterized by both $\mathrm{C}$ and $\mathrm{E}$. However, the relative amounts of these two characteristics are different at each level (see Fig. 4). At any given level of development, E-characteristics are most prevalent for the least differentiated systems, and C-characteristics for the most differentiated ones. Thus, E- and C-characteristics are most marked at the opposite ends of the systemic continuum.

We prefer to talk about consciousness rather than cognition. There are many different definitions for cognition, from simply listing different functions and processes (e.g., memory, language processing, problem solving, thinking) to defining adaptive activities of individuals. We define cognition as a process of active interaction with the environment that produces knowledge as a means of achieving goals. Or, in a broader sense, cognition is an effective action that enables an organism to continue to exist in an environment (Maturana, Varela, 1987). To gain knowledge means to learn individual acts and cooperative interactions (Maturana, 1970). Defined as such, cognition is a wider concept than C and E. The latter are regarded as specific aspects of cognition. Such a definition has similarities with views of, e.g., Schatter (1964), Dehaene (Dehaene, Naccache, 2001) and de Soussa (2003). In addition, a similar paring of $C$ and $\mathrm{E}$ is reflected in understanding $\mathrm{E}$ as an antagonist of rationality (Delgado, 1966; De Sousa, 2003) and reason (Davidson, 2000; Dolan, 2002) and in considering rationality as a distinctive characteristic of C (Block, 1995). 


\section{Theoretical background}

Reality is both objective and subjective (Midgley, 1994; Searle, 1992). We have examined formation and realization of subjective experience (SE) in animals and humans with neurophysio-logical methods (Alexandrov, Yu.I., Grechenko, Gavrilov, et al., 2000) and consider E and C as important aspects characterizing its dynamics. In order to describe the neuronal basis of SE, we first define the elements of SE.

Properties of a brain are not a sum of properties of single neurons but instead emerge as a result of dynamic interaction of the neurons within a system (Milner, Squire, Kandel, 1998; Mountcastle, 1995). The neural equivalent of an element of SE, established during the formation of a new behavior and realized in behavior, is defined as an organization of a group of neurons composing the system. A well-developed systemic approach to the neuronal bases of behavior is based on P. Anokhin's theory of functional systems (for a review, see (Anokhin, P.K., 1973)). Of importance in this theory is the definition of a system-creating factorthe result of a system-a desired relation between an organism and environment achieved through the realization of that system. The principal determinant of a system is not a stimulus, an event in the past, but a future result of the behavior. Thus, a system is understood as a dynamic organization of activity of components in different anatomical localizations, both in the brain and in the rest of the body. The interaction of components provides an adaptive result for an organism.

The interaction of neurons while achieving a behavioral result is accomplished by synchronizing the activity of the neurons in different brain structures (Aleksandrov, I.O., Maksimova, 1985). Interestingly, a very similar suggestion but related to the "binding" problem was developed later and has gained considerable experimental support ((Roelfsema, Engel, Konig, et al., 1997); see also (Thatcher, 1997)). Synchronization of neurons located in different brain areas has been suggested to be important in understanding C (Engel, Fries, KoËnig, et al., 1999; Thompson, Varela, 2001).

Another key concept in the theory of functional systems is development. Both concepts, development and results of a system, are merged into the concept of systemogenesis. Systemogenesis refers to the idea that during early ontogeny those differently localized elements of the nervous system and body that are essential for achieving the results of the systems undergo selective and accelerated maturation, assuring the survival of the organism at the early stages of individual development (Anokhin, P.K., 1973).

Shvyrkov (1986) suggested that systemogenesis takes place also during adult development because the formation of a new behavioral act is always a formation of a new system. The principal factor in understanding the role of different neurons in the organization of behavior is the history of behavioral development, i.e., the history of the successive systemogeneses (Alexandrov, Yu.I., 1989; Alexandrov and Alexandrov, 1982). The system-selective concept of learning (Shvyrkov, 1986) is in line with the idea of a selective, rather than instructive, principle underlying learning (Edelman, 1987). This concept considers the formation of a new system to be a fixation of the stage of individual development-the formation of a new element of SE during learning.

The neural basis of this process is the specialization of "reserve" (silent) neurons, but not a change in specialization of already specialized units. New neurons appearing in neoneurogenesis are also likely to be involved in this process (Shoers, Miesegaes, Beylin, et al., 2001), in which a new system is added to the existing ones (Alexandrov, Yu.I., Grechenko, Gavrilov, et al., 2000; De Sousa, 2003). It does not substitute the previously formed systems, but instead is "superimposed" on them. Neurophysiological studies have demonstrated that specialization of recently specialized neurons does not change during a single-unit recording lasting for weeks and even months, and that there are many silent neurons in different brain areas (Bradley, Burns, et al., 1996; Chang, Sawyer, et al., 1994; Jog, Kubota, Connolly, et al., 1999; Swadlow, Hicks, 1997; Thompson, Best, 1990; Wilson, McNaughton, 1993; Woodward, Janak, Chang, 1998).

It has been shown (Alexandrov, Yu.I., Brushlinskij, et al., 1999; Alexandrov Yu.I., Grechenko, Gavrilov, et al., 2000; Shvyrkov, 1986) that complex instrumental behavior is realized by a new system that was formed during learning of the acts composing this behavior, and by the simultaneous realization of older systems (Fig. 1) formed at previous stages of individual development (see also Fig. 3). The latter may be involved in many behavioral patterns, i.e., they may belong to elements of SE that are common for various acts (Fig. 1). Therefore, behavior is the realization of the history of behavioral development. Multiple systems, each fixing a certain stage of development of the given behavior, are involved. 
BEHAVIORAL ACT 1 BEHAVIORAL ACT 2

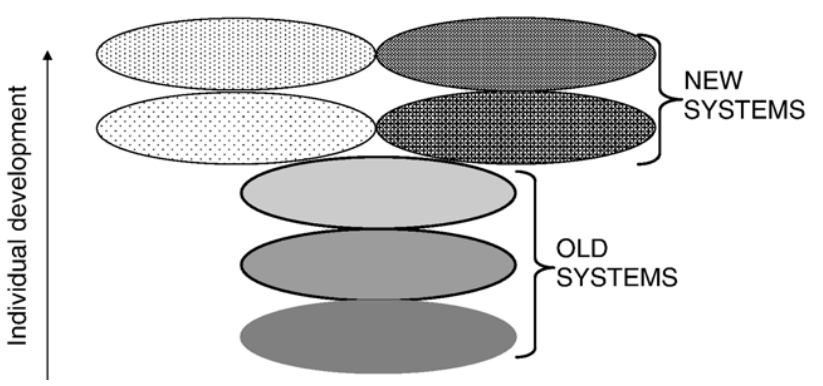

Figure 1. Systemic structure of behavior. Two different behavioral acts consist of both old systems which are common to both of them, and of new systems developed later. The course of individual development is indicated by the arrow

Our single-unit recordings during instrumental behavior have demonstrated that neurons with new specializations are abundant in cerebral cortex, whereas phylogenetically archaic and peripheral structures contain very few such neurons (Alexandrov, Grechenko, Gavrilov, et al., 2000). Systems may differ in level, intricacy and quality of a result achieved. Neurons participating in a functional system are located in different anatomical areas.

The ideas presented above are fundamental for systemic cognitive neuroscience, which suggests a systemic solution to the mind-body problem (Shvyrkov 1978; 1990). In this solution, the organizing of physiological processes into a system is based on specific systemic processes. Their substrate is physiological activity, whereas their informational content is mental. Mental processes that characterize an organism and behavioral act as a whole, and physiological processes that take place at the level of separate elements cannot be related directly, but only through the informational systemic processes. Mental events cannot be related directly to the localized elementary physiological events, but rather to the systemic processes of their organization. Psychological and physiological descriptions are partial descriptions of the same systemic processes. We stress that systemic processes involve not only the brain but also the whole body. Thus, the term mental characterizes the organization of activity not only in neurons but also in other anatomical structures of the organism.
This solution of the mind-body problem was formulated about a quarter of a century ago. It resembles Hegel's "neutral monism" (see in (Priest, 1991)) arguing that mind and physical are two aspects of united reality. Chalmers (Chalmers, 1995, p. 215) formulated a double-aspect principle: "Information (or at least some information) has two basic aspects, a physical aspect and a phenomenal aspect". We would replace "some information" with "informational systemic processes", i.e., processes which organize elementary mechanisms into a functional system.

\section{Stream of consciousness}

Behavior is considered to be active and aimed at a future event-the result. A fundamental process is the prediction of the consequences of a behavioral (perceptual) act. In the following section, we shall elaborate the idea that comparison of the predicted and achieved results is the essence of $\mathrm{C}$. The process of matching the predicted and actual parameters of an event has also been considered a basic content of $\mathrm{C}$ by others, but they were regarding the stimulus as an event (Edelman, 1989; Ivanitsky, 1995; John, Easton, Isenhart, 1997; Gray, 1995; Grossberg, 1999).

The role of $\mathrm{C}$ in behavior is commonly understood in the terms of "Cartesian theatre". Behavior is considered as a continuum from stimulus to response, a special "perceptive system" providing "input" to a central thinking arena, which in turn controls systems governing bodily motion (Dennett, 1993). It is very difficult to eliminate the Cartesian theatre if one sticks to a traditional stimulus- response paradigm (see, e.g., (Pribram, 1999)). However, systemic cognitive neuroscience may be a step towards an alternative. In it, the behavioral act is not considered as an isolated entity, but as a component of a continuum of behavioral acts. The next act is realized after the result of the previous act is achieved and evaluated. Evaluation is a necessary part of the organizational processes of the next act. It is a transitional process from the realization of one act to that of the subsequent act (Fig. 2). In this perspective, behavior is a continuum of achieving results (Anokhin, P.K., 1978). Environmental changes, traditionally considered to be stimuli for a given act, are informationally linked with the preceding behavior in the course of which these changes were anticipated in the model of future behavioral resultthe goal of behavior. We suggested above that realization of any behavioral act is subserved by a simultaneous activation of many systems of 


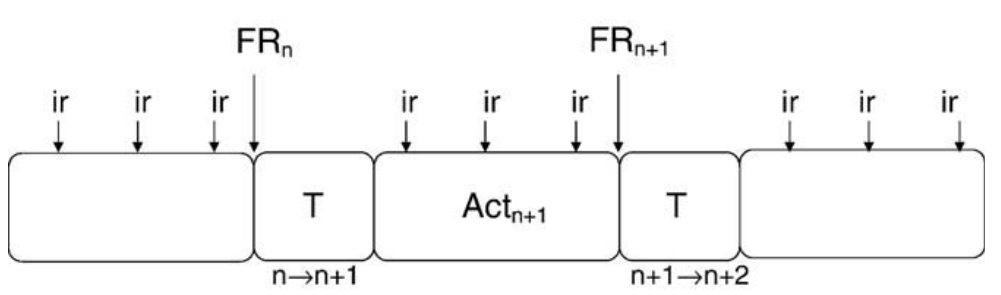

Figure 2. Behavioral continuum as a continuum of results. ir = intermediate result, $F R=$ final result of a given behavioral act, $\mathrm{Act}=$ behavioral act. $\mathrm{T}$ refers to transitional processes from a preceding to the following act. More details in the text

different ages. Thus, transitional processes between behavioral acts may be viewed as stages in which activity in one set of functional systems (elements of SE) is replaced by another set.

Two types of neurons are active during transitional processes: (1) those related to the realization of the preceding and following behavioral acts, and (2) additional neurons not related to realization of either of these acts (Aleksandrov, I.O., Maksimova, 1985; Alexandrov, Yu.I., Grechenko, Gavrilov, et al., 2000; Shvyrkov 1978; 1990). During "coactivation" of neurons, the states of simultaneously active neurons belonging to the systems of different acts are coordinated. Activations of additional neurons also involve the elements of SE which do not subserve realizations of the preceding and following acts. Transitional process is not merely an overlap of the two systemic processes, it is a specific systemic process itself.

Transitional processes determine intersystemic relations that are not an exact copy of previous behaviors. Reorganization of these relations is the most important feature of the transitional process. Transitional systemic processes include (i) evaluation of the achieved result; (ii) organization of the next act, depending on evaluation and (iii) reorganization of relations among the systems of the just realized act (Alexandrov, Yu.I., 1999a; Alexandrov, Yu.I., Brushlinskij, et al., 1999; Shvyrkov 1978; 1990).

Results can be intermediate or final (Fig. 2). Both types of results are compared with predicted behavioral outcomes. Comparison of intermediate results is necessary for the appropriate deployment of consecutive phases within a behavioral act. The comparison of the predicted and achieved final result reveals the correspondence between the achieved organism-environment relation as a whole and the relation that was planned when the behavioral act was formed.

Comparison of the predicted and actual parameters of an event, the content of $\mathrm{C}$, occurs constantly during behavior. Organisms do not anticipate and match the stimuli, but rather the intermediate and final results. Thus, we connect $\mathrm{C}$ with evaluation of predicted and achieved results at different levels of behavioral organization.

C operates at different levels in individual mind (see also (Damasio, 2000; Dennett, 1993; Edelman, 2003; Fessard, 1954; Freeman, 1990; Granit, 1977; Tulving, 1985; Zeki, 2003; Zelazo, 2004)). Comparison of the parameters of intermediate results with the predicted ones during the realization of a behavioral act corresponds to the first level of $\mathrm{C}$. Transitional processes from one behavioral act to another (comparison of the actual and predicted parameters of the final result of the behavioral act) correspond to the second, "higher", level of C. Evaluation of intermediate results perhaps takes much less time than that of the final result (Alexandrov, Yu.I., Grinchenko, 1979; Jeannerod, 1999; Libet, 1993, p. 201). C exists in an indefinite range of degrees (Searle, 1990). Thus, the two levels of $\mathrm{C}$ actually refer to two categories of levels.

Now, we can give a working definition of $\mathrm{C}$. The content and significance of $\mathrm{C}$ are the evaluation by an organism of its relation to environment during the realization of a behavioral act (external or internal) and during transitional processes between acts. Evaluation depends on content of individual experience and results in its continual updating. Fig. 2 helps to conceive the relation of stream of consciousness to the stream of systemic organization of the behavioral continuum. There are different levels of $\mathrm{C}$ that are related to the stream of final results and intermediate results. Interestingly, Seche-nov suggested already a century ago that C is a chain of links. In a similar vein, Crick and Koch (Crick, Koch, 2003) propose that visual C is a "series of snapshots".

\section{Consciousness and emotion: similar roles}

Vygotsky defines $\mathrm{E}$ and $\mathrm{C}$ quite similarly in different articles. He suggests that $\mathrm{E}$ is an "evaluative reaction of an organism on its own behavior" (Vygotsky, 1982, p. 94) and defines C as "reaction of an organism on its own reactions" (Vygotsky, 1982, p. 58). This similarity is not accidental. 
In addition to its role in the control of an individual's behavior, $\mathrm{C}$ is also crucial in communication. $\mathrm{C}$ provides for high-level interactions with other conscious beings (Frith, 1995). In humans, use of language in social interaction is an important "carrier" of C. It is essential in the collective achievement of results (Rubinshtein, 1989; Vanderwolf, 1998). "Conscious facts" can be shared through communication with others (Hilgard, 1980; Simonov, 1994). Using language, individuals can evaluate their own behavior (give a self-report) and also share this evaluation with others. Language areas of the brain are involved in the organization of behavior even when overt verbalization is not required (Ivanitsky, 1993; Ivanitsky, 1995; Nishitani, Hari, 2000).

As is generally agreed, $\mathrm{E}$ is formed early in ontogeny. We argue that it has significance comparable to that of $\mathrm{C}$ in the control of activity. How ever, the SE involved in this process does not yet contain language-coded elements of social experience. This is why E and C appear so different if $\mathrm{C}$ is considered only with respect to its highest language-dependent selfreflective role. Also, E may be considered as related to the evaluation of correspondence between the program of actions and its actual realization ((Reykowskij, 1979), cf. level 1 of C). Like C, E appearing during the termination of realization of behavioral acts is related to the comparison of predicted and actual parameters of results ((Anokhin, P.K., 1978), cf. level 2 of $\mathrm{C}$ ).

Dynamics of $\mathrm{E}$ and $\mathrm{C}$ on a behavioral continuum are also similar. Both are related to the process of achievement of a result during the realization of action and to the evaluation of achieved results. Their roles include control and sustenance of behavior as well as its activation and termination (Anokhin, P.K., 1978; Rolls, 1986; 1999; Rubinshtein, 1989; Strongman, 1987). Facial expression and nonlinguistic vocalizations related to $\mathrm{E}$ suggest that $\mathrm{E}$ also has an important communicative role (Izard, 1977). Emotion and consciousness at successive stages of individual development $\mathrm{E}$ and $\mathrm{C}$ appear to have similar roles in behavior. Do we then actually use the two terms to describe different aspects of a single mechanism that is underlying behavior? In an attempt to answer this question, we will concentrate on individual development.

Formation of new elements of SE during development results in increasing differentiation of organism-environment relations (Alexandrov, Yu.I., 1989; Chuprikova, 1997; Edelman, 2003; Tononi, Edelman, 1998; Werner, 1948; Werner, Kaplan, 1956). Schneirla $(1939,1959)$ sug- gested that the most general division of behavior is that of approach and withdrawal. This division is appropriate to all behavior in all animals (Schneirla, 1959). The lowest, the earliest and the most common level of differentiation for all living beings is to approach "good" things and to withdraw from "bad" things (Dennett, 1993). This basic "approachwithdrawal" division of $\mathrm{E}$ is widely accepted (see (Davidson, Irwin, 1999)). We connect $\mathrm{E}$ to the most ancient and minimally-differentiated levels of the organization of behavior (for related views, see (Anokhin, P.K., 1978; Berntson, Boysen, Cacioppo, 1993; Cacioppo, Gardner, 1999; Davidson, Cacioppo, 1992; Davidson, Ekman, Friesen, Saron, Senulis, 1990; Goldfield, 1995; Panksepp, 2000; Panksepp and Panksepp, 2000; Schneirla, 1939; 1959; Zajonc, 1980)).

Systems subserving approach and withdrawal behaviors are formed during early prenatal life (Alexandrov, Yu.I., Brushlinskij, et al., 1999). These systems may be considered as early formed elements of SE that compose individual memory. Properties of these elements influence the features of later formed adult behavior (Gottlieb, 1971; Pedersen, Blass, 1981). These systems subserve achievement of proper nutrition. A fetus may also perform "defensive" actions and move to avoid potentially damaging influences (see (Alexandrov, Yu.I., Brushlinskij, et al., 1999)).

If even prenatal acts are directed at the achievement of adaptive result, behavior certainly is goal-directed and future-oriented in early postnatal infants (Bertenthal, 1996; Goldfield, 1995). After birth, infants use prenatally elaborated acts to approach and withdraw (Goldfield, 1995; Zelazo, 2004).

The ultimate result of most pre- and postnatal behaviors is nutrition. Gradually, this behavior becomes more differentiated. In each subsequent stage of development, organisms take into account additional environmental details to organize their behavior (see, e.g., in (Alexandrov, Yu.I., 1989; Khayutin, Dmitrieva, Alexandrov, L.I., 1997)). At the prenatal stage, various movements may lead to very similar nutritional outcomes (Alexandrov, Yu.I., Brushlinskij, et al., 1999). Then sucking behavior develops, shaped by many factors such as the concurrent activity of siblings. Gradually, the infant's food-acquisition behavior starts to depend on different food materials as well as on the specific need state of the individual.

It has been suggested that $\mathrm{E}$ has its origin in pleasant and unpleasant sensations that the infant and even the fetus experienced (Van der Veer, 1996). Some facial expressions of $\mathrm{E}$ are innate (Darwin, 1965; Gan- 


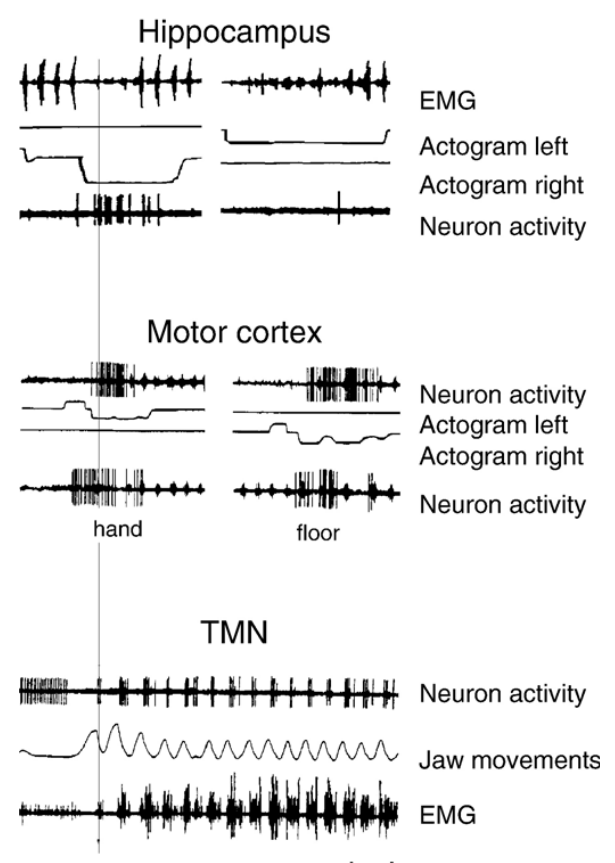

$\stackrel{\longmapsto}{\longmapsto 00 \mathrm{msec}}$

Figure 3. Recordings from hippocampus were made during instrumental foodacquisition behavior in which a rabbit acquired food by pressing one of the two pedals on left and right sides of the experimental cage. Pedal pressing caused food to appear in a feeder on the same side of the cage. The rabbit repeatedly carried out the food-acquisition task involving a constant sequence of acts (pedal pressing turning and going to the feeder, taking food from the feeder) on both sides of the cage (for details, see (Alexandrov, Yu.I., Grinchenko, Jarvilehto, 1989; Alexandrov, Yu.I., Grinchenko, Laukka, et al., 1990)). EMG shows activity of m. masseter during food seizure and mastication. In actograms, upward deflection means pressing the pedal and downward deflection means lowering of the head into the feeder. The hippocampal neuron was active in the right-wall (in figure on the left) but not in the left-wall cycle. The motor cortex neuron was active during both right-wall and left-wall cycles in the same instrumental food-acquisition behavior, but also when the animal received food from the experimenter's hand and took it from the floor. Neuron in the trigeminal mesencephalic nucleus (TMN) was active during seizure and mastication of food. Jaw movement actogram shows movements of the lower jaw during opening (up) and closing (down) of the mouth chrow, Steiner, Daher, 1983), observed even in prematurely born infants (Anokhin, P.K., 1978). We were born with "the mechanism of primary E" (Damasio, 1994). Thus, realization of the earliest forms of behavior is a sufficient condition for behavior to be emotional.

As Tononi and Edelman (Tononi, Edelman, 1998) noted, systemic complexity and differentiation can be used as measures of conscious experience. High complexity implies not only local specialization but necessarily global integration as well (Tononi, Sporns, Edelman, 1994; Tononi, Edelman, 1998). Complexity along with differentiation increases during development (Demetrius, 1997; Tononi, Edelman, 1998). From our viewpoint, development, and hence this increase in differentation, is based on the specialization of neurons in relation to newly formed more differentiated systems.

Human abilities to differentiate the environment are practically limitless, since we can use social experience, World III (the world of manmade culture, comprising the whole of objective knowledge (Popper, Eccles, 1977)), to increase the number of elements of SE. This qualitatively new, higher level of differentiation leads to a tremendous increase in $\mathrm{C}$-characteristics of behavior.

Fig. 3 demonstrates neurons which are specialized in relation to systems that were formed at different stages of individual development. The trigeminal mesencephalic nucleus starts to function at the earliest stage of ontogeny. A majority of the neurons of the anterolateral motor cortex (jaw area) become specialized later during the formation of the behavioral act of food seizure. The hippocampal neuron is specialized at the latest stage of ontogeny during learning of instrumental food-acquisition behavior in the experimental cage. The neuron in the trigeminal mesencephalic nucleus is active during each jaw movement in the seizure of the food, grinding and regular mastication. The neuron in the anterolateral motor cortex is active in more specific situations: during the seizure of food from various sources such as different foodboxes (near opposite walls of the experimental cage), from the floor or from experimenter's hand. The hippocampal neuron is active in an even more specific situation: during the seizure of food from a certain food-box and not from the floor or hands. Vertical thin line indicates that, during seizure from the appropriate food-box, all these neurons belonging to the systems of different age and levels of differentiation are active simultaneously. 
The structure of SE becomes more complex due to both the increase in the number of elements of SE and of the interactions among them. As a result, the behavioral repertoire becomes larger. However, this diversity can be classified into two groups, approach and avoidance, since the repertoire being formed is constructed using "good" or "bad" classification resulting from a basic set of values that each individual possesses (Damasio, 1994).

Early forms of food-acquisition behavior are examples of evolutionary-fixed approach acts in the positive E domain (E+). An early evolving avoidance "freezing" behavior is an example of the negative E domain (E-). Later, many other goal-directed withdrawal behaviors, with specific emotional feelings, evolve. For example, withdrawal from feces and carrion and the accompanying subjective feeling of disgust are adaptive (Efroimson, 1995). The same object may be related to opposite E in different organisms: hyenas approach carrion.

\section{United concept of consciousness and emotion}

As stated earlier, performance of a behavioral act is subserved by the simultaneous realization of systems corresponding to both minimal and maximal levels of differentiation. Later evolving forms of mental life do not annihilate early "primitive" ones (see also (Ribot, 1901; Werner, 1948)). Rather, C and E may be considered as characteristics of different levels of systemic organization of the given behavioral act that correspond to different levels of the environment's differentiation. Each of these levels is a transformed stage of individual development fixed in memory as systems that were formed during learning. It is impossible to define when $\mathrm{C}$ appears. At each successive stage, as differentiation of systems grows, C-characteristics increase. C and E are linked characteristics of the same whole systemic organization. Each developmenta and differentiation level is necessarily characterized by both $\mathrm{C}$ and $\mathrm{E}$. Consequently, any change to this organization will cause some changes in both $\mathrm{C}$ and $\mathrm{E}$. However, $\mathrm{C}$ - and E-characteristics are not equal for all systems; they are maximally prominent at the most and least differentiated systemic levels, respectively.

E-characteristic of behavior is related to which domains of individual experience are actualized: approach $(\mathrm{E}+)$ or withdrawal (E-) (from the third-person perspective). For the subject of behavior (the first-person perspective), it means a basic classification of things and events as good or bad (Damasio, 1994). This is a coarse nonlinguistic description and is used for the self-report about the results of actions already at the earliest stages of ontogeny. This is why we often cannot verbalize the reasons for our attraction or repulsion to things and events (Zajonc, 1980). Thus, even though $\mathrm{E}$ is related to the individual's self-evaluation of behavior and its results just like $\mathrm{C}$, it is its relation to the results of those systems that ensures the individual's relation to the environment at a low level of discretization.

The C-characteristic of behavior is related to which new systems are actualized out of the many different possibilities existing in individual's memory (the third-person perspective). Haggard et al. (Haggard, Clark, Kalogeras, 2002) have shown evidence of "binding" of awareness of the voluntary action and its effect, attracted together across time. In terms of our concept, it means that matching of intermediate and final results form a unit for the subject (the first-person perspective). What we have described are not two different first-person perspectives (E and $\mathrm{C}$ ), but rather two aspects of the same perspective.

The two meanings of E may cause confusion: (1) E as a characteristic of low-differentiated evolutionary and onto-genetically old systems and (2) E as a characteristic of highly differentiated systems that are formed in a cultural context using language and thought and based on social feedback. Verbal description of subjects' relation with their environment uses World III terms (Popper, Eccles, 1977) and includes classification of the current relation using culturally understood concepts (e.g., "fear", "pleasure") if the intensity of the E-characteristic (see below) is high enough. Social feedback is used in "emotional education", when an individual learns to understand his or her own subjective feelings and desires, and to cope with them (Buck, 1989). The subjective experience of E, "how each emotion feels" (Ekman, 1999a) is a "mixture" of rough global and discrete cultural World III descriptions. Recent experiments have shown the involvement of the evolutionarily newest "C-related" cortical structures in "emotional behavior". The prefrontal cortex, connected to conscious processes and specific human cognitive abilities (Quartz, 1999), is regarded also as an important area for emotional behavior (Davidson, Irwin, 1999; Rolls, 1999). This brain area may play an important role in the aforementioned mixing of descriptions.

While Fig. 2 illustrated the dynamics of SE during behavior, Fig. 4 illustrates its systemic structure based on the basic and ontogenetically old 


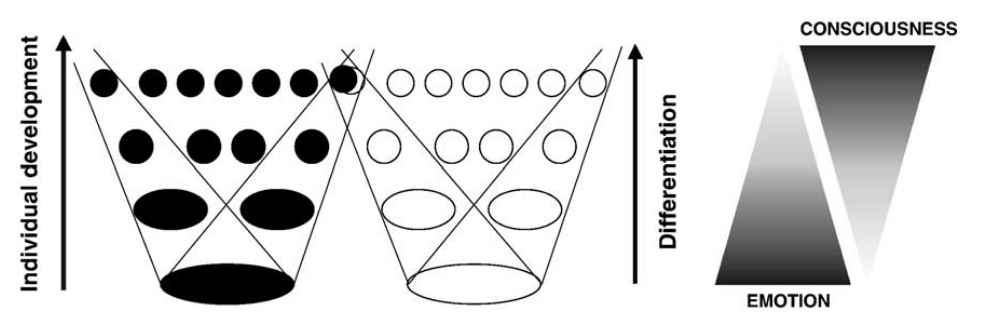

Figure 4. Consciousness and emotion at successive stages of differentiation. At the bottom, the two big ovals symbolize the earliest low-differentiated systems subserving the first forms of behavior: approach (white) and withdrawal (black). Differentiation increases upwards. Lines delineate the sets of systems of different ages. The simultaneous realization of these systems subserves achieving results of different behavioral acts. Triangles illustrate the view that emotion and consciousness are characteristics of an integrated multilevel systemic organization of behavior; they also illustrate that the levels of differentiation differ in relative amount of these characteristics

approach-withdrawal division. The two old systems (black E- and white $\mathrm{E}+$ ) are connected in memory with other old withdrawal or approach systems. They are more differentiated than the oldest ones but a mass of even more differentiated systems has formed after them. Because of this systemic differentiation, we have a continuum of fine-grained emotional states, not just two.

Fig. 4 shows the E+ and E- domains as conceptually similar. However, experimental results indicate that withdrawal behavior is more demanding with respect to environmental cues than approach behavior (Alexandrov and Alexandrov, 1993; Khayutin, Dmitrieva, Alexandrov, L.I., 1997). This suggests that $\mathrm{E}$ - is more differentiated than E+ (Damasio, 1994). Larger diversity of $\mathrm{E}$ - means more possibilities to act. In this sense, we are "more conscious" when experiencing negative emotions.

\section{Similarities and differences between our and other approaches}

Our theoretical background and united concept of $\mathrm{C}$ and $\mathrm{E}$ differ in many respects from more traditional thinking. To clarify our conceptualization, we first review literatures sharing at least some of our ideas. After that, we will emphasize the aspects of this approach which we think are original to us.

\subsection{Similarities}

McDougall (McDougall, 1938) considered the search for food and avoidance of harmful events as two primary "strivings". All other strivings subsequently develop from these primitive forms by differentiation. Ortony et al. (Ortony, Clore, Collins, 1988) also regarded positive and negative as two basic and minimally differentiated types of affective responses, forming a basis for further increasing differentiation. They considered these types as minimally differentiated forms of $\mathrm{E}$, and their further development as reflecting increasing differentiation.

In our view, the prenatally-formed oldest systems are connected in memory with slightly younger systems inside the approach and withdrawal domains. Rather similarly, Lang et al. (Lang, Bradley, Cuthbert, 1990) argue that E space is organized according to a basic appetitivedefensive dimension. They criticize the view that there are several independent basic emotions-disgust, fear, anger, joy, sadness, surprise-and propose that their specificity is Ftactical (specific context-bound patterns of action), not Fstrategical (defined by broad end goals). Liotti et al. (Liotti, Brannan, Egan, et al., 2001) also developed ideas about the common origin of different Es and have presented experimental evidence in support of a common brain mechanisms for primary emotions.

Behavior of postnatal infants is not highly differentiated (see in (Fraisse, Piaget, 1963)). Early-formed systems provided a neural basis to what Koffka (1921) called "emotion-like perceptions" that are basic for the subsequent development of C. Krueger (Krueger, 1930) suggests that separate perceptions, ideas, volitional acts, all originate from diffuse emotional states. Zajonc (1980) concluded that "good-bad" is the first and most basic discrimination that an individual learns in ontogeny. In normal behavior, learning to "discriminate" means establishing specific goaldirected approach and withdrawal behaviors. This approach-withdrawal dichotomy is clearly observable in newborn infants (Goldfield, 1995).

Importantly, this dichotomy exists throughout ontogeny. Highly differentiated systems can be divided according to this basic dichotomy. All conscious states, as Searle (2000) claims, come to us from the pleasure-unpleasure dimension. Berntson et al. (Berntson, Boysen, Cacioppo, 1993) also hold that the basic evaluative dimension (approach- 
withdrawal) is not peculiar to the specific neuraxial level and may be characteristic of all levels in the neuronal subserving of behavior.

How is it in phylogeny? Do we agree that $\mathrm{E}$ is the maternal basis for all other mental events (Krueger, 1930), that affect is primary in phylogeny (Zajonc, 1980), that $\mathrm{E}$ was set in evolution before the appearance of $C$ (Damasio, 2000) and that $C$ is evolutionarily based on primal emotions (Liotti, Brannan, et al., 2001)? No, because in our perspective, there was never a moment in evolution when E-characteristics existed without C-characteristics. Yes, because lower species, e.g., snails, are more Faffective than humans. Humans have much more differentiated systems and much longer "distance" between old and the newest systems. The ratio of new/old systems is high in humans, and this is why we are more conscious than other organisms.

C does not came to humans "as a sudden illumination" (Eccles, 1992, p. 7320; Edelman, 2003). Clifford $(1874 ; 1886)$ wrote more than a century ago that if we accept evolution, we also have to accept that even in the lowest organism such as amoeba there is something of a shared nature with our own C.

In any individual, it is possible to select the systems corresponding to the different levels of environment's differentiation, from minimal $(\mathrm{E})$ to maximal (C). By definition, this division is valid for all organisms that have individual development because development means formation of more differentiated systems. Therefore, we agree with Buck (Buck, 1989) that not only complex, but also even simple organisms have $\mathrm{E}$ and also "intelligence" (Trewavas, 2003). When a fish gets on a hook, it does not merely show bodily manifestations of negative emotions (Randerson, 2003), but actually experiences them (Sneddon, Braithwaite, Gentle, 2003 Randerson, 2003). If a snail self-stimulates its mesocerebrum, this means that it likes the effect of stimulation and realizes approach behavior with $\mathrm{E}+$ characteristic. Then, as suggested by the authors, the mesocerebrum has an 'emotional' role in behavior (Balaban, Maksimova, 1993).

Evaluation of an action's results is present in all animals and may be related to proto-C and proto-E. The content of SE involved in these processes differs from that in humans. Animals use only their own experience of relations with their environment or in rare occasions the experience of individuals they have had a direct contact with (Whitehead, 1998; Whiten, Goodall, McGrew, et al., 1999). Humans use, in addition, the products of social reflection accumulated in World III (Pop- per, Eccles, 1977). The use of World III terms (words, ideas, etc.) means that while evaluating the results of own behavior, a human being looks at himself "through the eyes of society". Therefore, human culture influences $\mathrm{C}$, but also has an impact on $\mathrm{E}$.

In the course of the differentiation of behavior, the number of behavioral acts shared by different emotions might increase. Outwardly similar actions may be used both to approach and to withdraw. Such "common acts" are marked in Fig. 4 as the overlapping of the E+ and E- systems. The emotional palette of behavior may therefore be very diverse due to the connections in the structure of memory between these systems representing different $\mathrm{E}$ domains. This complexity is the reason why we have so-called mixed states (Plutchik, 1962).

We agree with Damasio that "innate circuits" (old low-differentiated systems) participate not just in bodily regulation but also in the activity of the evolutionarily modern adult brain areas (Damasio, 1994). Since the subserving of any behavior necessarily involves early maturing systems, E of certain intensity is an intrinsic characteristic of all behaviors. This is in agreement with Buck's (1989) statement that we always feel hunger and thirst, happiness and anger, etc., but often weakly which causes us to ignore the feelings. It is also consistent with Zajonc's (1980) view that feeling accom-panies all cognition. Damasio's (2000) view also presupposes this obligatoriness, and even the continuous presence of E ("background") in any behavior, but this E is not necessarily felt. He considers E as "scaffolding" which has arisen during development and which servers as the foundation for conscious, cognitive processing (Damasio, 1994). Ellis and Newton (Ellis, Newton, 2000) also think that E underlies all conscious states.

Since any behavior is a simultaneous realization of both low and highly differentiated systems, the first-person perspective at any given moment includes $\mathrm{C}$ - and E-characteristics. It means that $\mathrm{E}$ contributes to the phenomenal $\mathrm{C}$ and vice versa. This proposition agrees with Ellis's (1999) opinion that E penetrates phenomenal C and is thus inseparable from the latter.

We agree with Damasio $(1994 ; 2000)$ that treating C and E as separate localizable entities is a mistake. This error in conceptualization is widespread because it fits well with the traditional Cartesian paradigm that is the foundation for the thinking of many researchers (Dennett, 1993). Our concept does not follow the Cartesian paradigm and sug- 
gests that $\mathrm{C}$ and $\mathrm{E}$ be studied not as separate entities but as E- and Ccharacter-istics, each applicable to all systems composing behavior. Our postulate of the whole-organism nature of these systems is in line with the statement that $\mathrm{C}$ cannot be identified with a fixed set of brain areas (Dehaene, Naccache, 2001). Davidson (2000) also claims that it is impossible to define special brain areas dedicated to $\mathrm{E}$ and C.

Agreeing with Rolls (1999), we do not think that there exists a special additional mechanism of the somatic marker's evaluation as introduced by Damasio (1994; 2000). However, we disagree with Roll's argument that "visual" behavior does not demand activity in somatosensory cortex. It certainly does. Moreover, we think that Searle (2000) is right in saying that he does not believe we will find visual $\mathrm{C}$ in the visual system or auditory $\mathrm{C}$ in auditory one. Rather, we will find single, "unified conscious field" containing different aspects of C. If a unisensory stimulus (visual or auditory) is behaviorally significant, its presentation leads to the simultaneous activation of neurons in numerous brain areas (e.g., in both the visual and somatosensory cortex during visual stimulation (Aleksandrov, Maksimova, 1985; Olds, Disterhoft, Segal, 1972)). The body and somatosensory "system" are involved in organization of any kind of behavior, even in the imagination of behavior (Jeannerod 1999).

We argued that the E-characteristic is related to the global division of behavior while the $\mathrm{C}$-characteristic is related to the selection from a huge repertoire of situationally and individually specific systems of behavioral acts. As Zajonc (1980) puts it, we may verbalize or think of something in an infinite variety of ways, but we have only a handful of emotions.

We related appearance of the E-characteristic with the formation of the oldest systems in ontogeny that are directed to the achievement of basic metabolic results. This is in an agreement with Panksepp's idea (Panksepp, 2000) that "neurobiological systems" mediating E subserve behaviors needed to cope with survival needs and allow newborn organisms to deal with values.

We argue that $\mathrm{C}$ and $\mathrm{E}$ are characteristics of the same whole systemic organization. With respect to C, others have presented similar opinions (Dennett, 1993). Ellis (1999) considers C as one aspect of a selforganizing system including the whole brain and the whole organism. In a similar vein, some colleagues have suggested that $C$ is an aspect of activity or an aspect of organization of biosystems that represent diverse aspects of experience but not a separate mechanism or a "product" of a certain neuronal circuitry (Deikman, 1973; Kinsbourne, 1995; Neisser, 1976; Thompson, Varela, 2001).

Vanderwolf et al. (Vanderwolf, Kelly, et al., 1988, p. 46, 56) wrote: "... it is doubtful that "emotion" is valid category of cerebral function. There is little scientific basis for the common belief that folk psychology concepts such as "emotion" or "motivation" actually correspond to natural anatomical and functional entities in the brain. Consequently, traditional psychological concepts may often provide misleading guides for the investigation of the control of behavior by the brain. Recent... findings suggest that functional studies of the "limbic system" must deal with behavior... and that one should not assume, a priori, that traditional philosophical and psychological categories of the mind have any sort of unified representation in the brain". We agree with this view. However, we strongly argue that both $\mathrm{E}$ and $\mathrm{C}$ are useful concepts. They indeed originate from folk psychology, in which mental processes and states have common-sense, not precise definitions (Churchland, 1986) and may be considered as "cultural constructions" (p. 56). These concepts are used in everyday life to explain and predict behavior and in most practical situations they work well (Midgley, 1994). However, they influence "the science proper" as well. For instance, when the plan is to study neuronal mechanisms of $\mathrm{E}$, it is assumed that if the concept of "emotion" exists, it must have a special physiological mechanism.

We can attribute to both E and C what Schouten (1999) said about C. Although it may be that $\mathrm{C}$ does not have "natural-kind status", it is impossible to deny the existence of $\mathrm{C}$ or claim that the common sense concept of $C$ has nothing to do with anything real. Concepts of $E$ and $C$ have been used fruitfully across centuries of philosophical, psychological and physiological inquiry. They are useful in understanding behavior both from the first- and the third-person perspectives, as well as in revealing the relations between these views.

\subsection{Differences}

The following paragraphs concentrate on those features in our conceptualization that we think to be the most original and unique to us. Some of these ideas might have been proposed also by others, but we 
believe our contribution is combining them into a consistent theoretical framework. The systemic approach and emphasis on the activeness of organisms are increasingly popular in attempts to construct a concept of C and E (Ellis, 1999; Ellis, Newton, 2000; Freeman, 1997; Jordan, 1998; Thompson, Varela, 2001; Vandervert, 1998). We base our conceptualization on theoretical and experimental research of the systemic organization of behavior made during the last 70 years (see (Alexandrov, Yu.I., Brushlinskij, 1999; Alexandrov, Yu.I., Grechenko, Gavrilov, et al., 2000; Anokhin, P.K., 1973; Shvyrkov 1978; 1990)). We argue that our theoretical background is the most consistent and the least eclectic in modern systemic neuroscience. It avoids concepts derived from the Cartesian paradigm. It argues that behavior is determined by the result of action, not by a stimulus. Furthermore, it argues that behavior should not be explained by a succession of neural activity from sensory to motor structures. Rather, realization of behavior is based on developing successive systemic processes, each of these processes being subserved by whole-brain integration.

A key concept is a result that is not a new state of an organism or a new state of environment but a new organism-environment relation that can be objectively described and defined in time. The achievement of the result can be experimentally related with the activity of a whole organism as well as also with the activity of its neuronal elements (Alexandrov, Yu.I., 1989; 1999a; Alexandrov, Yu.I., Brushlinskij, et al., 1999; Alexandrov, Yu.I., Grechenko, Gavrilov, et al., 2000; Anokhin, P.K., 1973; Shvyrkov, 1986; 1978; 1990). That is why within our conceptual framework, single-unit neurophysi-ology may be used to describe the dynamics of $\mathrm{C}$ and $\mathrm{E}$ as characteristics of an organism-environment relation as a whole as effectively as is done in cognitive neuroscience using noninvasive methods like EEG, MEG and fMRI (O'Regan, NoeË, 2001; Thompson, Varela, 2001).

Understanding functions as functional systems that cannot be localized in separate brain structures and that include the whole organism avoids "boxology" and the corresponding view that $\mathrm{C}$ and $\mathrm{E}$ are separate localizable entities or independent modules-concepts criticized also by others (Damasio, 1994; 2000; Ellis, Newton, 2000; Thompson, Varela, 2001). It helps in avoiding "boxology" both on the theoretical level and in interpreting experimental data. Dynamics of the activity of any given brain structure may be related to the dynamics of $\mathrm{C}$ and $\mathrm{E}$ via the de- scription of the specialization of the neurons in that structure belonging to low- or high-differentiated systems.

The future-directed nature of $\mathrm{C}$ and $\mathrm{E}$ is not an additional characteristic of the system that may appear in behavior. It is an intrinsic characteristic of the organization of an individual at all levels: from behavior to single unit activity (Alexandrov, Yu.I., 1999a) and from the ancient, prenatally formed systems to the maximally differentiated systems which are formed in relation with complex elements of social experience.

The content of $\mathrm{C}$ is related not to the analysis of stimuli or "sensorimotor coupling" as usually thought (see, however (Jordan, 1998; Vandervert, 1995)), but through constructing models of results of both overt and covert behavior which are then compared to these models with actually achieved results. An important aspect of our concept is that the dynamics of behavior is described as successive achievement of intermediate and final results composing a behavioral continuum. This succession makes it easier to understand the continuous nature of $\mathrm{C}$.

The suggested concept is applied to processes occurring at different time scales: phylogenesis, individual development, learning a behavioral act and the realization of a behavioral act. It stresses the similarity of $\mathrm{C}$ and $\mathrm{E}$ as characteristics of isomorphous systems with a similar architecture. $\mathrm{C}$ and $\mathrm{E}$ are not entities, neither independent nor complementary. Rather, they are different characteristics of a single entity-the set of systems that are actualized in the given behavior.

E does not influence or activate C. Neither do E and C interact, because two different characteristics of the same entity cannot influence each other. There is no behavior lacking emotional basis, since any actualized set of systems is based on low-differentiated systems. It is not appropriate to speak about specific systems or mechanisms producing $\mathrm{C}$ and $\mathrm{E}$, since all systems are aimed at achieving less or more differentiated results. $\mathrm{C}$ and $\mathrm{E}$ are characteristics that are inherent to various systems composing the set to differing extents.

Our conceptualization does not use the "spotlight metaphor" tightly linked with the "Cartesian theatre", a metaphor which is a characteristic of the majority of theories of $\mathrm{C}$ even when not mentioned explicitly (Shanon, 2001). Our concept avoids this metaphor because we treat C and $\mathrm{E}$ not as products of activity of isolated structures but as characteristics related with the whole-organism integration. 


\section{Explanatory and predicting}

\section{capability of the concept}

There is considerable evidence of specialized brain structures for negative and positive emotions (Cacioppo, Gardner, 1999; Davidson, Ekman, Friesen, et al., 1990; O’Doherty, Kringelbach, Rolls, et al., 2001). This is in line with observations showing that neurons with similar specialization are often located close to each other (Alexandrov, Yu.I., Grinchenko, Jarvilehto, 1989; Hampson, Simeral, Deadwyler, 1999), and that while some structures contain many neurons belonging to a given system, in others there are just a few of them (Alexandrov, Yu.I., 1989; Alexandrov, Yu.I., Grinchenko, Laukka, et al., 1991; Alexandrov, Yu.I., Brushlinskij, et al., 1999). We suggest that the existence of structures strongly related to positive or negative emotions means that many neurons of this structure belong to relatively low-differentiated systems aimed at approach or withdrawal. In other words, E- and E+ reflect different sets of actualized systems (see Fig. 4).

In addition to the brain, different sets refer also to other elements of body. Body parts, many of which mature at the earliest stage of ontogeny, belong to the low-differentiated system. Therefore, the organization of activity of these elements, as well as that of autonomous nervous system (ANS) differs in different emotions. Different sets of muscles are involved in behavior with different emotional valences (Tassinary, Cacioppo, 1992). Moreover, ANS activity is different not only during E+ and E- but also during negative emotions such as fear and disgust (Ekman, 1984; 1999a). Since E-characteristics are related to the realization of old, low-differentiated systems (formed during early ontogeny and persisting during the whole life of an individual), all of these differences are present in both young and old organisms (Levenson, 1992). However, in certain anatomical structures, there are subpopulations of neurons with very different specializations. Some belong to old systems of approach and withdrawal behaviors, others to the newest systems. For example, in the accessory olfactory bulb of rabbits, some neurons are selectively active during withdrawal and others during approach (Kumar, Dudley, Moss, 1999). Some neurons in both the anterior and posterior cingulate cortex of rabbits, rats and monkeys belong to the old systems, but some are specialized to the newest ones. Some neurons are specialized to discharge during approach behavior, while others do so only during withdrawal (Alexandrov, Yu.I., Grechenko, Gavrilov, et al., 2000; Alexandrov, Yu.I., Grinchenko, Bodunov, et al., 2000; Gavrilov, Grinchenko, Alexandrov, Yu.I., 1998; Hutchison, Davis, Lozano, et al., 1999; Singer, Seymour, O’Doherty, et al., 2004; Shima, Aya, Mushiake, et al., 1991). Mapping studies suggest that the human cingulate areas are involved in both emotional (positive or negative) and cognitive tasks, and hence are involved in both $\mathrm{E}$ and $\mathrm{C}$ (see, e.g., (Bush, Luu, Posner, 2000; Damasio, 2000)). Our interpretation of these data is that the cingulate cortex contains separate neuron populations with different specializations. For a similar reason (Alexandrov, Yu.I., Grinchenko, Laukka, et al., 1993), the hippocampus has been suggested to be involved in both "cognitive and emotional processes" (McNaughton, 1997).

Existence of brain structures that are strongly related to realization of, for example, low-differentiated systems and that demonstrate the relation with E-characteristic of behavior does not mean that these structures "produce" E. E-characteristics do not disappear in more differentiated systems, and cannot be related exclusively to one system or group of systems. It just is more marked in low-differentiated systems (Fig. 4). It characterizes a whole-organism systemic integration. Finally, cells belonging to low-differentiated systems are found, in different amounts, in numerous brain structures (Alexandrov, Yu.I., 1989; Alexandrov, Yu.I., Grinchenko, Laukka, et al., 1991; Alexandrov, Yu.I., Grinchenko, Laukka, et al., 1993; Alexandrov, Yu.I., Grechenko, Gavrilov, et al., 2000; Shvyrkov, 1986).

Experimental data indicate that all neurons do not act as selectively as described above. Often, the same neurons are activated in widely different behaviors, e.g., both in approach and withdrawal. While some new systems develop as elements of the E- or E+ memory domain (subserving realization of only withdrawal or approach), others subserve behavioral acts that may be used in both behaviors (white and black overlapping in Fig. 4). Realization of such "common" acts creates an impression that the same act would be used in different emotional situations, but the acts only look similar. When a monkey uses the same bar pressing to avoid a shock and to obtain a reward, different sets of 'barpressing units' are active in the cingulate cortex. Some neurons are active only if monkey performs bar pressing during approach, others only during withdrawal, and the rest during both acts (Nishijo, Yamamoto, 
Ono, et al., 1997). Different neurons in the monkey cingulate cortex are active during the same act when it is performed to avoid pain or to obtain a reward (Koyama, Kato, et al., 2001). This means that outwardly similar acts are represented by different, yet somewhat overlapping, sets of old and new systems. Thus, we can explain results showing that an apparently identical action that is included in different activities can have opposite emotional valences (Leont'ev, 1971).

Earlier we discussed the overlap of new systems that are formed while learning instrumental acts. However, different behaviors that belong to E+ or E-domains partly overlap at the level of the oldest systems (see also Fig. 4). In other words, different behavioral acts within a given domain may be based on one and the same low-differentiated system. Indeed some functional similarity seems to exist also between different needs. For example, food-acquisition behavior may be activated in thirsty animal when water is inaccessible (Fraisse, Piaget, 1963). Systems that are formed in prenatal ontogeny seem to ensure the achievement of metabolic results of a fetus, ensuring sucking (Alexandrov, Yu.I., Brushlinskij, et al., 1999; Pedersen, Blass, 1981). Such a common system later differentiated into feeding and drinking.

Zajonc (1980) proposed the existence of "preferanda" for such global features of environment that allow quick classification of the affective character. It is assumed that the amygdala is involved in the unconscious use of behaviorally relevant emotional features while cortical structures are responsible for the conscious usage of environmental details (Morris, OË hman, Dolan, 1999; Whalen, Rauch, Etcoff, et al., 1998). There also is evidence that evaluation of a situation starts from global meaning and ends with conscious identification (McCauley, Parmelee, et al., 1980). Ekman (1984) suggests that there are universal situations, common to different cultures, that act as elicitors of emotions. For us, global and common to different cultures means related to archaic low-differentiated systems with pronounced E-characteristic. The number of these systems is small if we compare it with that of the high differentiated systems (Fig. 4). It is easy to select behavior of this small set and, consequently, $\mathrm{E}$ is in the beginning of action and many elicitors can give rise to E nearly immediately (automatic appraisal). Selection from a small set means also little information.

However, selection at the low level of differentiation is important. It outlines a domain of memory that may be used in the given situa- tion (Fig. 4). This makes the search for the required material from memory easier and limits the domain used for the operation, and helps our reasoning process to operate efficiently (Damasio, 2000). Additionally, $\mathrm{E}$ also operates as a basic decision making mechanism without the involvement of reason (Damasio, 1998). For example, when visual perception is impaired because of massive lesions in the striate cortex (blindsight), one can be "led by emotions" to recognize facial expression without awareness (De Gelder, 2000).

Animals approach or avoid rough imitations of natural objects. For example, appearance of a red oblong object mimicking the red abdomen of a concurrent male provokes fighting behavior in sticklebacks during spawning season. Systems that subserve such behaviors are species specific and phylogenetically fixed, formed early in ontogeny, low differentiated and may be actualized by presentation of "preferanda". Individual development goes from global "preferanda" to detailed "discriminanda". On the other hand, the earlier developmental stages of behavior are characterized by greater emotionality. Indeed, there is a shift during ontogeny from perceiving objects in terms of holistic, overall aspects to decomposing objects into separate dimensions (Goldstone, 1998). The younger an individual is, the more emotional it is (Fraisse, Piaget, 1963; Panksepp, 1994b).

$\mathrm{E}$ is a characteristic of systems aimed at the certain adaptive result of behavior. When we speak about $\mathrm{E}$ at early ontogenetic stages, we assume that a given E-characteristic must appear in individual development together with a specific behavior into which corresponding low-differentiated systems are included. Infants who do not move around are not afraid of heights. When they start to move, their wariness of high places appears (Bertenthal, 1996; Campos, Bertenthal, Kermoian, 1992).

Relation of $\mathrm{E}$ to the formation of behavioral systems means that differences in behavior of different species imply differences in E-characteristics of their behavior. At the same time, there is a continuity of emotional expressions from lower animals to humans (Darwin, 1965). Some emotional expressions are similar in different species (Ekman, 1999b). The similarities exist even though the set of early behavioral acts in animals belonging to different species differs significantly. Some old patterns in the organization of the nervous system appear in present species with minor modifications (Krubitzer, 1995). Communication using emotional expressions characterizes the earliest-formed systems, and its 
many aspects are innate (Plutchik, 1991). Behavior of different species is based on similar systems that are formed prenatally or at early postnatal stages (see above). Thus, a basic continuity of emotional expressions may be due to interspecies similarities in the realization of systems formed at the earliest stages of individual development.

These systems are actualized together with more differentiated ones and are connected with them. Facial expression is a characteristic of realization of older systems. However, subjective description of the emotional state, as a result of emotional education, belongs to higher levels of systemic differentiation. Expression and description appear together because they are characteristics of the same unity: simultaneously active older and newer systems during a behavioral act. Because systems of higher differentiation were formed under cultural influence and because older and newer systems must be coordinated, it is reasonable to expect interspecies similarities along with intraspecies differences. These differences result from variations of environment where an individual developed, e.g., from cultural differences. As an example, culture influences facial expressions (Ekman, 1984; 1999). Thus, E does not reflect only biology, but also depends on social and cultural influences.

The influence of cultural factors is manifested in use of language to describe our relation with environment. Such description may also use terms belonging to different emotions. Damasio (2000) notes that $\mathrm{C}$ may be considered as both a feeling of emotions and as a usage of language for the translation from the nonverbal language of body. This "translation" of individuals' actions results into the language of society which takes place at the border between neighboring acts on a behavioral continuum. This translation occurs during transitional processes and is included in the content of a second level of $\mathrm{C}$ (see Fig. 2). When subjects describe a succession of events, words referring to E occur at episode boundaries, i.e., in the beginning or in the end of event (Bamberg, 1997). These boundaries coincide with the deployment of transitional processes. Thus, description of one's own emotional state is included in planning of actions. In line with this suggestion, Cacioppo and Gardner (Cacioppo, Gardner, 1999) suggest that the ability to monitor one's own emotions is as important a determinant of life successes as traditional measures of intelligence.

Above, we have analyzed explanatory capabilities of our united concept of $\mathrm{E}$ and $\mathrm{C}$. In the following, we use the concept to formulate hypotheses and test them experimentally. We analyze the brain mechanisms underlying intensity of $\mathrm{E}$. $\mathrm{E}$ has two dimensions: affective valence and intensity (Lang, Bradley, Cuthbert, 1990). Valence was extensively discussed above. We suggest that the most important factor influencing the intensity of $\mathrm{E}$ is the relative proportions of low- vs. high-differentiated systems activated during a given behavior. The higher the proportion of low differentiated systems, the higher is the intensity of E. We hypothesize that suppression of elements belonging to the highly differentiated systems leads to an increase of E-characteristic. Experimental refutation of this hypothesis would be considered as inconsistent with a fundamental premise of our concept.

A shift in relative weight of two sets of systems can be experimentally induced by acute ethanol administration. Acute ethanol injection $(1 \mathrm{~g} / \mathrm{kg})$ decreases number of active neurons in the cingulate cortex. The number decreases because of selective suppression of neurons belonging to the newest systems (Alexandrov, Yu.I., Grinchenko, Laukka, et al., 1990). We observed an analogous tendency in an EEG experiment with human subjects. We recorded ERPs while the subjects categorized words spoken in a foreign and native language. Acute ethanol administration $(1 \mathrm{ml} / \mathrm{kg})$ affected significantly more the ERPs elicited by words spoken in a foreign language (Alexandrov, Yu.I., Sams, Lavikainen, et al., 1998). All subjects became euphoric during the experiment and felt that classification task was easier after drinking. Nevertheless, the number of classification mistakes increased. These results can be explained by assuming that alcohol has a selective suppressive influence on those neurons that subserve the actualization of experience accumulated at later stages of individual development. Their suppression means that the proportion of low-differentiated systems increases. This fits well with subjects' increased emotionality. We have also shown that alcohol intoxication is reflected in psychological test performance. When the subjects had the same dose of alcohol as in the above-described EEG experiment, their emotionality again increased significantly (Bodunov, Bezdenezhnych, Alexandrov, Yu.I., 1997).

Supporting our findings that alcohol selectively blocks neurons belonging to the most differentiated systems, Curran and Hildebrandt (Curran, Hildebrandt, 1999) showed that alcohol significantly weakens conscious but not unconscious recognition. Tiihonen et al. (Tiihonen, Kuikka, Kupila, et al., 1994) used positron emission tomography to study 
cerebral blood flow in males during orgasm. They found a decrease of blood flow in all cortical areas except in prefrontal cortex where blood flow increased. Neurons specialized in relation to highly differentiated systems are abundant in cortical areas (Alexandrov, Yu.I., Grechenko, Gavrilov, et al., 2000). Interestingly, activity was increased only in prefrontal cortex. This area, as we already mentioned, may be specifically involved in the estimation of "emotionality" of the situation in terms of World III. The same area becomes active after acute administration of alcohol inducing euphoria (Tiihonen, Kuikka, Hakola, et al., 1994). Panksepp and Panksepp (2000) summarize data showing that when humans have intensive emotions, cortical regions tend to be silent. On the other hand, removal of neocortex in rats leads to increased emotionality (Panksepp, 1994a).

The relative weights of the two sets of systems change during complex behavior. Intensity of $\mathrm{E}$ changes accordingly. The closer an individual is to the final result of complex behavior, the higher is the old/ new ratio. In instrumental behavior (Fig. 3), this ratio increases in the final act of the behavioral sequence (taking of food) if compared to the preceding act-pedal pressing. During both acts, units belonging to new as well as to old systems are active, but during the final act, more old units and less new units are active. During the preceding act, pedal pressing, the reverse is true (Alexandrov, Yu.I., 1989; Alexandrov, Yu.I., Grinchenko, Laukka, et al., 1990; Alexandrov, Yu.I., Grinchenko, Laukka, et al., 1991; Alexandrov, Yu.I., Grinchenko, Laukka, et al., 1993; Gorkin, Shevchenko, 1996). We predict that if the ratio of old/new systems increases during progression of complex sequential behavior, intensity of E increases in parallel. Striving for goal-object may be assessed as a peculiar indicator of E. Striving increases as the animal approaches the goal (Fraisse, Piaget, 1963).

Other factors influencing intensity of E include: (1) the ratio of systems belonging to the certain emotional valence and "common" systems elements which may be active in during E+ and E-. This could be described as a degree of homogeneity of E. (2) The strength of actualization of old systems. Thus, the longer the time from receiving nutritional substances, the stronger is neural activation in subcortical structures and the strive to obtain these substances (Kendrick, Baldwin, 1989; Woodward, Janak, Chang, 1998; Yamamoto, Matsuo, et al., 1989).

\section{From emotion to consciousness and back}

In the process of ontogeny and phylogeny, as well as during the behavioral acts, the systemic structure of behavior changes. In the following, we discuss how this is reflected in the E- and C-characteristics of behavior.

Learning starts when an organism has no appropriate knowledge in memory to solve a new problem and can classify the situation only globally as good or bad. Approach or withdrawal should be realized but they cannot involve appropriate more differentiated systems. In such a situation, the old/new ratio and hence the intensity of $\mathrm{E}$ is increased. Two ways of experience reorganization may take place: a "routine" change by assimilating a new event in the frame of existing memory scheme (due to the reorganization of relations among its elements) and a "heuristic" act of creating a new memory and reorganization of preexisting schemes (Piaget, 1951; Polanyi, 1958). The less we know about the situation, the higher the weight of older systems and thus the greater the intensity of $\mathrm{E}$. In addition, there is a higher probability that reorganization of relations between preexisting elements of individual experience is not enough for the solving of the problem especially in the latter case. The systemo-genesis, i.e., formation of new element of SE, should begin.

Cahill and McGaugh (Cahill, McGaugh, 1998) have shown that the more emotional a learning condition is, the stronger that long-term memory develops. However, we suggest that intensity of $E$ is not a cause of the memory formation. Rather, intensive $\mathrm{E}$ is a characteristic of systemic structure inherent to such a relation between available experience and challenge of a problem that demands the formation of new system.

In the process of learning, the number of new systems grows, and, consequently, the degree of differentiation of environment-individual relations increases. Schouela et al. (Schouela, Steinberg, et al., 1980) argue that learning how to behave in a new environment means a change from the rough global to the more detailed behavioral forms. They conclude that this demonstrates the orthogenetic principle: development proceeds from a state of relative lack of differentiation to increasing differentiation, with the older and later evolved forms coexisting (Werner, Kaplan, 1956).

Bechara et al. (1997) demonstrated transition from the former to the later stage of learning. In a gambling task, subjects began to behave advantageously before they consciously realized their strategy. They also generated an anticipatory skin conductance response when they made 
a choice that turned out to be risky. This finding means, in our terms, that the global, low-differentiated "E stage" changed to more discrete C stage (creation of newest system together with conscious report or self-report). Similar results were earlier obtained by Tikhomirov (Tikhomirov, 1975), who suggested a stage of Femotional presolution that preceded the conscious solution of a task.

Regularity similar to that occurring during learning, a shift from rough global to more detailed forms, may also occur in the execution of a definitive behavioral act. McCauley et al. (1980) asked their subjects to label target pictures preceded by either semantically related or unrelated prime pictures. Their data show that perceptual recognition may be described as a progression starting from a quick stage of semantic processing, the result of which is "tacit" general knowledge of the meaning of the stimulus. This is followed by a second stage that includes conversion of tacit to "explicit" knowledge that underlies conscious identification: the picture is named. Thus, the deployment of the behavioral act moves from general to specific (McCauley, Parmelee, et al., 1980).

Some molecular-genetic and morphological processes underlying learning and memory consolidation recapitulate processes used during ontogeny (Anokhin, K.V., 2000; Singer, 1995). We suggest another important aspect related to the similarity between the two. In both cases, processes start from the most global (older) systems and end with the creation of differentiated (newer) ones.

We already discussed studies showing that ontogenetic development is directed from global to discrete forms. If it is so, and if the old/ new systems ratio is an important factor influencing intensity of $\mathrm{E}$, we anticipate that the early ontogenetic stage is more emotional than the older one because acquiring new systems in the course of individual development means that the old/new systems ratio increases progressively. Obviously, infantile behavior is less conscious (Zelazo, 2004) and more emotional (O'Regan, NoeË, 2001), and the younger a child is, the more emotional it is (Fraisse, Piaget, 1963; Panksepp, 1994b).

There is an order of maturation of behaviors based on the use of different sensory modalities. Behavior based on chemical senses belongs to the oldest ones, audition appears later and visual sense is the most recent one (Gottlieb, 1971). We assume that appearance of a new modality, i.e., the possibility to create new more differentiated systems, increases the C-characteristic of individual behavior. Thus, behavior based on earlier emerging modalities is more emotional than that based on later ones. This is also reflected in different languages, since a language is used to describe the relation of individual and environment in terms of culture. Indeed, in many languages (e.g., English, Japanese and Zulu), two thirds to three quarters of words describing sensory impressions refer to vision and hearing, and the remaining minority to all other senses (Wilson, 1998). The same tendency is observed for Russian (Alexandrov, Yu.I., Kolbeneva M.G., unpublished data).

Richardson and Zucco (1989) have suggested that there is a weak connection between olfactory experience and language. Herz and Cupchik (1992) found that memories associated to odors do not require words to be elicited. If the low level of differentiation of odor-related memory systems is related to their "age", this memory should be older than others. Indeed, odor-related memories appear to belong to the oldest ones (Herz, Cupchik, 1992).

Mature organisms normally use multisensory information. Sometimes, especially in experimental conditions, a single modality may be critical to achieve an adaptive result. The more prominent role of olfaction in eliciting emotional memories, in comparison to vision and audition, has been demonstrated in many experiments ((Herz, 1998; Herz, Cupchik, 1992; 1995; Hinton, Henley, 1993), but see (Alaoui-Isma"1li, Vernet-Maury, et al., 1997)). Royet et al. (2000) suggest that odorants' strong ability to induce emotional states is related to the superior potency of olfaction over vision and audition in activating the amygdala. This does not mean that visually-guided behavior is always less emotional than olfactory-guided behavior but only that the relative weight of old systems in the latter case is often higher than in the former one.

Werner and Kaplan (1956) analyzed phylogeny using the orthogenetic principle mentioned above. Phylogenetic development may be considered as increasing the maximal differentiation of systems in a given species. As a result, humans have much more choices than other species (Panksepp, 1994b). Also, von Uexkull (1957) suggested that during evolution organisms can perform an increasing number of acts and their world becomes more discrete.

We have a general principle: as one moves from the old low-differentiated systems to the newer more differentiated ones, one moves "from emotion to consciousness". In this sense, ontogeny recapitulates phylogeny, learning recapitulates ontogeny and act execution recapitulates 
learning. Certainly, the time scales of phylo-, ontogenetical and learning processes are different. They range from centuries, years and months to hours and minutes.

We demonstrated in the previous section that alcohol consumption increases the relative weight of less differentiated, older systems If we consider development as a way from low to high differentiation, alcohol in healthy individuals reverses this. Such transient modification of individual's experience structure, determined by suppression of the most differentiated systems, is characterized by the increased emotionality and a growing number of behavioral mistakes. An individual's relation with environment becomes less discrete and easier. This could be one of the reasons why people drink alcohol. It also is a reason why alcohol intoxication increases errors in performance. In alcoholics, the acute administration of alcohol causes the opposite effect: the number of active neurons belonging to new systems increases and the weight of highly differentiated systems increases. It is paralleled by the decrease of E- and increase in the effectiveness of performance (see in (Alexandrov, Yu.I., Grinchenko, Bodunov, et al., 2000)). Thus, in alcoholics, alcohol administration is associated with a shift from $\mathrm{E}$ to $\mathrm{C}$.

\section{Conclusion}

We have presented a theoretical framework to aid in understanding of the concepts of emotion and consciousness in terms of systemic structure of behavior. This framework allows bridging objective and subjective descriptions of emotions and consciousness. We argue that emotion and consciousness should not be regarded as separate psychological processes with distinct neurophysiological mechanisms. Both characterize similar functions in goal-directed behavior, but with different aspects and at different levels. Therefore, behavior is simultaneously emotional and conscious. What differs is the relative amount of these two characteristics, connected to developmentally older and newer systems composing the behavioral act.

\section{Acknowledgments}

We thank Dr. Antti Revonsuo and two anonymous reviewers for helpful comments, and Steve Zecker for editing the language.

\section{References}

Alaoui-Isma“1li, O., Vernet-Maury, E., et al. (1997). Odor hedonics: connection with emotional response estimated by autonomic parameters. Chem. Senses, 22. P. 237-248.

Aleksandrov, I.O., Maksimova, N.E. (1985). P300 and psychophysiological analysis of the structure of behavior. Electroencephalogr. Clin. Neurophysiol., 61. P. 548-552.

Alexandrov, L.I., Alexandrov, Yu.I. (1993). Changes of auditory-evoked potentials in response to behaviorally meaningful tones induced by acute ethanol intake in altricial nestlings at the stage of formation of natural behavior. Alcohol, 10. P. 213-217.

Alexandrov, Yu.I. (1989). Psihofiziologicheskoe znachenie aktivnosti tsentral'nyh $i$ perifericheskih neyronov $v$ povedenii [Psychophysiological significance of the activity of central and peripheral neurons in behavior]. Moskva: Nauka.

Alexandrov, Yu.I. (1995). Soznanie i emotsii [Consciousness and emotion]. Teoriya deyatel'nosti i sotsial'naya praktika. 3-y mezhdunarodnyj kongress [Theory of Activity and Social Practice. Proceedings of the 3-d International Congress]. Moskva: Rossijskoe psikhologocheskoe obsshestvo. P. 5-6.

Alexandrov, Yu.I. (1999a). Psychophysiological regularities of the dynamics of individual experience and the "stream of consciousness". In C. Teddei-Ferretti, C. Musio (eds.). Neuronal Bases and Psychological Aspects of Consciousness. Singapore: World Scientific. P. 201-219.

Alexandrov, Yu.I. (1999b). Comparative description of consciousness and emotions in the framework of systemic understanding of behavioral continuum and individual development. In C. Teddei-Ferretti, C. Musio (eds.). Neuronal Bases and Psychological Aspects of Consciousness. Singapore: World Scientific. P. 220-235.

Alexandrov, Yu.I., Alexandrov, I.O. (1982). Specificity of visual and motor cortex neurons activity in behavior. Acta Neurobiol. Exp., 42. P. 457-468.

Alexandrov, Yu.I., Brushlinskij, A.V., et al., (1999). Sistemnie aspekty psikhicheskoy deyatelnosti [Systemic aspects of mental activity]. In K.V. Sudakova (ed.). Moskva: Editorial URSS.

Alexandrov, Yu.I., Grinchenko, Yu.V. (1979). Ierarhicheskaya organizatsiya elementarnogo povedencheskogo akta [Hierarchical organization of the elementary behavioral act]. In V.B. Shvyrkova (ed.). Sistemnye aspekty neyrofiziologii povedeniya (Systemic Aspects of Neurophysiology of Behavior). Moskva: Nauka. P. 170-234.

Alexandrov, Yu.I., Grinchenko, Yu.V., Bodunov, M.V., et al. (2000). Neuronal subserving of behavior before and after chronic ethanol treatment. Alcohol, 22. P. 97-106.

Alexandrov, Yu.I., Grechenko, T.N., Gavrilov, V.V., et al. (2000). Formation and realization of individual experience: a psychophysiological approach. In R. Miller, A.M. Ivanitsky, P.V. Balaban (eds.). Conceptual Advances in Russian Neuroscience: Complex Brain Functions. Concept. Adv. Brain Res., 2. Amsterdam: Harwood Academic Publishers. P. 181-200. 
Alexandrov, Yu.I., Grinchenko, Yu.V., Jarvilehto, T. (1989). Is there functional reorganization of intact brain areas after local brain damage? Rep. Fac. Educ., 2. University of Oulu. P. 1-40.

Alexandrov, Yu.I., Grinchenko, Yu.V., Laukka, S., et al. (1990). Acute effect of ethanol on the pattern of behavioral specialization of neurons in the limbic cortex of the freely moving rabbit. Acta Physiol. Scand., 140. P. 257-268.

Alexandrov, Yu.I., Grinchenko, Yu.V., Laukka, S., et al. (1991). Acute effects of alcohol on unit activity in the motor cortex of freely moving rabbits: comparison with the limbic cortex. Acta Physiol. Scand., 142. P. 429-435.

Alexandrov, Yu.I., Grinchenko, Yu.V., Laukka, S., et al. (1993). Effect of ethanol on hippocampal neurons depends on their behavioral specialization. Acta Physiol. Scand., 149. P. 429-435.

Alexandrov, Yu.I., Sams, M., Lavikainen, J., et al. (1998). Differential effects of alcohol on the cortical processing of foreign and native language. Int. J. Psychophysiol., 28. P. $1-10$.

Alexandrov, Yu.I., Shvyrkov, V.B. (1974). Latentnye periody i sinhronnost' reaktsiy neyronov zritel'noy i somatosensornoy oblastey kory na uslovnuyu vspyshku sveta [Latencies and simultaneity of discharges of visual and somatosensory cortex neurons in response to conditioned light flash]. Neurophysiologia, 6. P. 551-553.

Anokhin, P.K. (1973). Biology and Neurophysiology of Conditioned Reflex and Its Role in Adaptive Behavior. Oxford: Pergamon Press.

Anokhin, P.K. (1978). Filosofskie aspekty teorii funktsional'noy sistemy (Philosophical Aspects of the Theory of Functional Systems). Moskva: Nauka.

Anokhin, K.V. (2000). Memory consolidation: narrowing the gap between systems and molecular genetic neurosciences. In R. Miller, A.M. Ivanitsky, P.V. Balaban (eds.) Conceptual Advances in Russian Neuroscience: Complex Brain Functions. Concept. Adv. Brain Res., 2. Amsterdam: Harwood Academic Publishers. P. 53-72.

Balaban, P.M., Maksimova, O.A. (1993). Positive and negative brain zones in the snail. Eur. J. Neurosci., 5. P. 768-774.

Bamberg, M. (1997). Language, concepts and emotions: the role of language in the construction of emotions. Lang. Sci., 19. P. 309-340.

Bechara, A., Damasio, H., et al. (1997). Deciding advantageously before knowing the advantageous strategy. Science, 275. P. 1293-1295.

Berntson, G.G., Boysen, S.T., Cacioppo, J.H. (1993). Neurobehavioral organisation and the cardinal principle of evaluative bivalence. Ann. N. Y. Acad. Sci., 702. P. 75-102.

Bertenthal, B.I. (1996). Origins and early development of perception, action, and representation. Annu. Rev. Psychol., 47. P. 431-459.

Block, N. (1995). On a confusion about a function of consciousness. Behav. Brain Sci., 18. P. 227-287.
Bodunov, M.V., Bezdenezhnych, B.N., Alexandrov, Yu.I. (1997). Izmeneniya shkal'nyh otsenok testovyh psihodiagnosticheskih metodik pri vozdeystvij alkogolya [The change of scale tests of psychodiagnostic methods under alcohol influence]. Psikhologicheskij zhurnal, 18. P. 95-102.

Bradley, P.M., Burns, B.D., et al. (1996). Electrophysio-logical correlates of prior training: an in vitro study of an area of the avian brain which is essential for early learning. Brain Res., 708. P. 100-108.

Brushlinskij, A.V. (2002). The interrelationship of the natural and the social in human mental development. J. Russ. East Eur. Psychol., 40. P. 16-31.

Buck, R. (1989). Subjective, expressive, and peripheral bodily components of emotion. In H. Wagner, A. Manstead (eds.). Handbook of Social Psychophysiology. University of Manchester: John Wiley and Sons Ltd. P. 199-221.

Bush, G., Luu, P., Posner, M.I. (2000). Cognitive and emotional influences in anterior cingulate cortex. Trends Cogn. Sci., 4. P. 215-223.

Cacioppo, J.T., Gardner, W.L. (1999). Emotion. Annu. Rev. Psychol., 50. P. 191-214.

Cahill, L., McGaugh, J.L.(1998). Mechanisms of emotional arousal and lasting declarative memory. Trends Neurosci., 21. P. 294-299.

Campos, J.J., Bertenthal, B.I., Kermoian, R. (1992). Early experience and emotional development: the emergence of wariness of heights. Psychol. Sci., 3. P. 61-64.

Chalmers, D.J. (1995). Facing up to the problem of consciousness. J. Conscious. Stud., 2. P. 200-219.

Chang, J.-Yu., Sawyer, S.F., et al. (1994). Electro-physiological and pharmacological evidence for the role of the nucleus accumbence in cocaine self-administration in freely moving rats. J. Neurosci., 14. P.1224-1244.

Chuprikova, N.I. (1997). Umstvennoe razvitie: Printsip differentsiatsii [Psychology of mental development: The Principle of Differentiation]. Moskva: Stoletie.

Churchland, P.S. (1986). Neurophilosophy. Toward a unified science of the mindbrain. London: A Bradford Book.

Clifford, W. (1874; 1886). Body and mind. In L. Stephen, F. Pollock (eds.). Fortnightly Review. London: Macmillan. Reprinted in Lectures and Essays.

Crick, F., Koch, Ch. (2003). A framework for consciousness. Nat. Neurosci., 6. P. 119-126.

Curran, H.V., Hildebrandt, M. (1999). Dissociative effects of alcohol on recollective experience. Conscious. Cogn., 8. P. 497-509.

Damasio, A.R. (1994). Descartes' Error: Emotion, Reason, and the Human Brain. New York: Grosset/Putnam Book.

Damasio, A.R. (1998). Emotion in the perspective of an integrated nervous system. Brain Res. Rev., 26. P. 83-86. 
Damasio, A.R. (2000). The Feeling of What Happens. London: Vintage.

Darwin, Ch. (1965). The Expression of the Emotions in Man and Animals. Chicago: University Chicago Press.

Davidson, R.J. (2000). Cognitive neuroscience needs affective neuroscience (and vice versa). Brain Cogn., 49. P. 89-92.

Davidson, R.J., Cacioppo, J.T. (1992). New developments in the scientific study of emotion: an introduction to the special section. Psychol. Sci., 3. P. 21-22.

Davidson, R.J., Irwin, W. (1999). The functional neuroanatomy of emotion and affective style. Trends Cogn. Sci., 3. P. 11-21.

Davidson, R.J., Ekman, P., Friesen, W.V., et al. (1990). Approach-withdrawal and cerebral asymmetry: emotional expression and brain physiology. J. Pers. Soc. Psychol., 58. P. 330-341.

De Gelder, B. (2000). Affective blindsight: are we blindly led by emotions? Trends Cogn. Neurosci., 4. P. 126-127.

Dehaene, S., Naccache, L. (2001). Towards a cognitive neuroscience of consciousness: basic evidence and a workspace framework. Cognition, 79. P. 1-37.

Deikman, A. (1973). The meaning of everything. In R.E. Ornstein (ed.). The Nature of Human Consciousness. San Francisco: W.H. Freeman and Co. P. 47-59.

Delgado, J.M.R. (1966). Emotions. Iowa: WM.C. Brown Company Publishers.

Demetrius, L. (1997). Directionality principles in thermodynamics and evolution. Proc. Natl. Acad. Sci. U. S. A., 94. P. 3491-3498.

Dennett, D.C. (1993). Consciousness Explained. London: Penguin Books.

De Sousa, R. (2003). In E.N. Zalta (ed.). The Stanford Encyclopedia of Philosophy. Spring edition. From: http://plato.stanford.edu/archives/spr2003/entries/emotion/.

Dolan, R.J. (2002). Emotion, cognition, and behavior. Science, 298. P. 1191-1194.

Eccles, J.C. (1992). Evolution of consciousness. Proc. Natl. Acad. Sci.U. S. A., 89. P. 7320-7324.

Edelman, G.M. (1987). Neural Darwinism: The Theory of Neuronal Group Selection. New York: Basic Books.

Edelman, G.M. (1989). The Remembered Present. A Biological Theory of Consciousness. NewYork: Basic Books.

Edelman, G.M. (2003). Naturalizing consciousness: a theoretical framework. Proc. Natl. Acad. Sci. U. S. A., 100. P. 5520-5524.

Efroimson, V.P. (1995). Genetika etiki i estetiki [Genetics of Ethics and Aesthetics]. Sankt-Peterburg: Talisman.

Ekman, P. (1984). Expression and the nature of emotion. In K. Scherer, P. Ekman (eds.). Approaches to Emotion. Erlbaum: Lawrence. P. 319-343.
Ekman, P. (1999a). Basic emotions. In T. Dalgleish, M. Power (eds.). Handbook of Cognition and Emotion. University of Manchester: John Wiley and Sons Ltd. P. 46-60.

Ekman, P. (1999b). Facial Expressions. In T. Dalgleish, M. Power (eds.). Handbook of Cognition And Emotion. University of Manchester: John Wiley and Sons Ltd. P. 301-320.

Ellis, R.D. (1999). Dynamical systems as an approach to consciousness: emotion, self-organization and the mind-body problem. New Ideas Psychol., 17. P. 237-250.

Ellis, R.D. Newton, N. (2000). The interdependence of consciousness and emotion, Conscious. Emot., 1. P. 1-10.

Engel, A.K., Fries, P., KoËnig, P., et al. (1999). Temporal binding, binocular rivalry, and consciousness. Conscious. Cogn., 8. P. 128-151.

Engel, K.A., Fries, P., Singer, W. (2001). Dynamic predictions: oscillations and synchrony in top-down processing. Nat. Rev., Neurosci., 2. P. 704-716.

Fessard, A. (1954). Mechanisms of nervous integration and conscious experience. In J.F. Delafresnaye (ed.). Brain Mechanisms and Consciousness. Springfield, IL: Charles C Thomas. P. 200-236.

Fraisse, P. Piaget, J. (1963). Traites de psychologie experimentale: V. Motivation, emotion et personnalite. Paris: Presses Universitaires de France.

Freeman, W.J. (1990). On the fallacy of assigning an origin to consciousness. In E.R. John (ed.). Machinery of the Mind. Boston: Birkhauser Boston, Inc. P. 14-26.

Freeman, W.J. (1997). Three centuries of category errors in studies of the neural basis of consciousness and intentionality. Neural Netw., 10. P. 175-1183.

Frith, C. (1995). Consciousness is for other people. Behav. Brain Sci., 18. P. 682-683.

Ganchrow, J.R., Steiner, J.E., Daher, M. (1983). Neonatal facial expressions in response to different qualities and intensities of gustatory stimuli. Infant Behav. Dev. 6, P. 473-484.

Gavrilov, V.V., Grinchenko, Yu.V., Alexandrov, Yu.I. (1998). Behaviorally specialized limbic cortex neurones in rats and rabbits: comparative study. Int. J. Psychophysiol., 30. P. 130 .

Goldfield, E.C. (1995). Emergent forms, Origins and Early Development of Human Action and Perception. New York: Oxford Univ. Press.

Goldstone, R.L. (1998). Perceptual learning. Annu. Rev. Psychol., 49. P. 585-612.

Gorkin, A.G., Shevchenko, D.G. (1996). Distinctions in the neuronal activity of the rabbit limbic cortex under different training strategies. Neurosci. Behav. Physiol. 26. P. 103-111.

Gottlieb, G. (1971). Ontogenesis of sensory function in birds and mammals. In E. Tobach, L.A. Aronson, E. Shaw (eds.). The Biopsychology of Development. New York: Academic Press. P. 67-128. 
Granit, R. (1977). The Purposive Brain. Cambridge: The M.I.T. Press.

Gray, J.A. (1995). The content of consciousness: a neuropsychological conjecture. Behav. Brain Sci., 18. P. 659-722.

Grossberg, S. (1999). The link between brain learning, attention and consciousness. Conscious. Cogn., 8. P. 1-44.

Haggard, P., Clark, S., Kalogeras, J. (2002). Voluntary action and conscious awareness. Nat. Neurosci., 5. P. 382-385.

Hampson, R.E., Simeral, J.D., Deadwyler, S.A. (1999). Distribution of spatial and nonspatial information in dorsal hippocampus. Nature, 402. P. 610-614.

Herz, R.S. (1998). Are odors the best cues to memory? A cross-modal comparison of associative memory stimuli. Ann. N.Y. Acad. Sci., 855. P. 670-674.

Herz, R.S., Cupchik, G.C. (1992). An experimental characterization of odorevoked memories in humans. Chem. Senses, 17. P. 519-528.

Herz, R.S., Cupchik, G.C. (1995). The emotional distinctiveness of odor-evoked memories. Chem. Senses, 20. P. 517-528.

Hilgard, E.R. (1980). Consciousness in contemporary psychology. Annu. Rev. Psychol., 31. P. 1-26.

Hinton, P.B., Henley, T.B. (1993). Cognitive and affective components of stimuli presented in three modes. Bull. Psychon. Soc., 31. P. 595-598.

Hutchison, W.D., Davis, K.D., Lozano, A.M., et al. (1999). Pain-related neurons in the human cingulate cortex. Nat. Neurosci., 2. P. 403-405.

Ivanitsky, A.M. (1993). Consciousness: criteria and possible mechanisms. Int. J. Psychophysiol., 14. P. 179-187.

Ivanitsky, A.M. (1995). Information synthesis in cortical areas as an important link in brain mechanisms of mind. Behav. Brain Sci., 18. P. 686-687.

Izard, C.E. (1977). Human Emotions. New York: Plenum Press.

Jeannerod, M. (1999). The 25 Bartlett lecture. To act or not to act: perspectives on the representation of actions. Q. J. Exp. Psychol., 52A. P. 1-29.

Jog, M.S., Kubota, K., Connolly, C.I., et al. (1999). Building neural representations of habits. Science, 286. P. 1745-1749.

John, E.R., Easton, P., Isenhart, R. (1997). Consciousness and cognition may be mediated by multiple independent coherent ensembles. Conscious. Cogn., 6. P. 3-39.

Jordan, J.S. (1998). Recasting Dewey's critique of the reflex-arc concept via a theory of anticipatory consciousness: implications for theories of perception. New Ideas Psychol., 16. P. 165-187.

Kendrick, K.M., Baldwin, B.A. (1989). The effects of sodium appetite on the responses of cells in the zona incerta to the sight or ingestion of food, salt and water in sheep. Brain Res., 492. P. 211-218.
Khayutin, S.N., Dmitrieva, L.P., Alexandrov, L.I. (1997). Maturation of the early species-specific behavior. The role of environmental factors. Physiol. Gen. Biol. Rev., 12. P. 1-45.

Kinsbourne, M. (1995). Septohippocampal comparator: consciousness generator or attention feedback loop? Behav. Brain Sci., 18. P. 687-688.

Koffka, K. (1921). Die Grundlagen der psychischen Entwicklung. Eine Einfü̈hrung in die Kinderpsychologie. Osterwieck a/H: Zickfeldt.

Koyama, T., Kato, K., et al. (2001). Anterior cingulated activity during pain-avoidance and reward tasks in monkeys. Neuro-sci. Res., 39. P. 421-430.

Krubitzer, L. (1995). The organization of neocortex in mammals: are species differences really so different. Trends Neurosci., 18. P. 408-417.

Krueger, F. (1930). Das Wesen der Gefu€hle. Entrourf eines systematishen Theorie. 3 And 4 unveranderte aufl. Leipzig: Verlag von Felix Meiner. P. 2-37.

Kumar, A., Dudley, C.A., Moss, R.L. (1999). Functional dichotomy within the vomeronasal system: distinct zones of neuronal activity in the accessory olfactory bulb correlate with sex-specific behaviors. J. Neurosci., 19. P. 1-6.

Lang, P.J., Bradley, M.M., Cuthbert, B.N. (1990). Emotion, attention, and the startle reflex. Psychol. Rev., 97. P. 377-395.

LeDoux, J.E. (2000). Emotion circuits in the brain. Annu. Rev. Neurosci., 23. P. $155-184$.

Leont'ev, A.N. (1971). Potrebnosti, motivy i emotsii (Needs, Motive, and Emotions). Moskva: Moskovskiy Gosudaestvennij Universitet.

Levenson, R.W. (1992). Autonomic nervous system differences among emotions. Psychol. Sci., 3. P. 23-27.

Lewin, K. (1935). A Dynamic Theory of Personality. New York: McGraw-Hill.

Libet, B. (1993). Neurophysiology of Consciousness. Boston: Birkhauser Boston, Inc.

Liotti, M., Brannan, S., Egan, G., et al. (2001). Brain responses associated with consciousness of breathlessness (air hanger). Proc. Natl. Acad. Sci. U. S. A., 98. P. 20352040.

Maturana, H.R. (1970). Biology of cognition. Biol. Comput. Lab. Res. Rep., 90. Urbana: University of Illinois.

Maturana, R.H., Varela, F.J. (1987). The Tree of Knowledge. Boston MA: Shambhala.

McCauley, C., Parmelee, C.M., et al. (1980). Early extraction of meaning from pictures and its relation to conscious identification. J. Exp. Psychol. Hum. Percept. Perform., 6. P.265-276.

McDougall, W. (1938). The Riddle of Life: A Survey of Theories. London: Methuen. 
McNaughton, N. (1997). Cognitive dysfunction resulting from hippocampal hyperactivity-A possible cause of anxiety disorder? Pharmacol. Biochem. Behav., 56. P. 603-611.

Milner, B., Squire, L.R., Kandel, E.R. (1998). Cognitive neuroscience and the study of memory. Neuron, 20. P. 445-468.

Midgley, M. (1994). The Ethical Primate. Humans, Freedom and Morality. London: Routledge.

Morris, J.S., OËhman, A., Dolan, R.J. (1999). A subcortical pathway to the right amygdala mediating ü̈nseen" fear. Proc. Natl. Acad. Sci. U. S. A., 96. P. 1680-1685.

Mountcastle, V.B. (1995). The evolution of ideas concerning the function of the neocortex. Cereb. Cortex, 5. P. 289-295.

Neisser, U. (1976). Cognition and Reality. San Francisco: W.H. Freeman and Co.

Nishijo, H., Yamamoto, Y., Ono, T., et al. (1997). Single neuron responses in the monkey anterior cingulate cortex during visual discrimination. Neurosci. Lett., 227. P. 79-82.

Nishitani, N., Hari, R. (2000). Temporal dynamics of cortical representation for action. Proc. Natl. Acad. Sci. U. S. A., 97. P. 913-918.

O’Doherty, J.O., Kringelbach, M.L., Rolls, E.T., et al. (2001). Abstract reward and punishment representations in the human orbitofrontal cortex. Nat. Neurosci., 4. P. 95-102.

Olds, J., Disterhoft, J.K., Segal, M. (1972). Learning centers of rat brain mapped by measuring latencies of conditioned unit responses. J. Neurophysiol., 35. P. 202-219.

O'Regan, J.K., NoeË, A. (2001). A sensorimotor account of vision and visual consciousness. Behav. Brain Sci., 24. P. 939-973.

Ortony, A., Clore, G.L., Collins, A. (1988). The Cognitive Structure of Emotions. New York: Cambridge Univ. Press.

Panksepp, J. (1994a). A proper distinction between affective and cognitive process is essential for neuroscientific progress. In P. Ekman, R.J. Davidson (eds.). The Nature of Emotion. Fundamental Questions. New York: Oxford Univ. Press. P. 224-226.

Panksepp, J. (1994b). The basics of basic emotion. In P. Ekman, R.J. Davidson (eds.). The Nature of Emotion. Fundamental Questions. New York: Oxford Univ. Press. P. 20-24.

Panksepp, J. (2000). The neuro-evolutionary cusp between emotions and cognitions: implications for understanding consciousness and the emergence of a unified mind science. Conscious. Emot, 1. P. 15-54.

Panksepp, J., Panksepp, J.B. (2000). The seven sins of evolutionary psychology. Evol. Cogn., 6. P. 108-131.

Piaget, J. (1951). Play, Dreams, and Imitation in Childhood. New York: Norton.

Pedersen, P.E., Blass, E.M. (1981). Prenatal and postnatal determinants of the first suckling episode in albino rats. Dev. Psychobiol., 15. P.349-355.
Plutchik, R. (1962). The Emotions: Facts, Theories, and a New Model. New York: Random House.

Plutchik, R. (1991). Emotions and evolution. In K.T. Strongman (ed.). Int. Rev. Stud. Emot., 1. Chichester: John Wiley and Sons. P. 37-58.

Polanyi, M. (1958). Personal Knowledge. Chicago: University of Chicago Press.

Popper, K.R., Eccles, J.C. (1977). The Self and It's Brain. Berlin: Springer.

Pribram, K.H. (1999). The self as me and I. Conscious. Cogn., 8. P. 385-386.

Priest, S. (1991). Theories of the Mind. London: The Penguin Books.

Quartz, S.R. (1999). The constructivist brain. Trends Cogn. Sci., 3. P.48-57.

Randerson, J. (2003). Does a hook hurt a fish? The evidence is reeling in. New Scientist, 3. P.15.

Reykowskij, J. (1979). Eksperimental'naya psihologiya emociy [Experimental Psychology of Emotion]. Moskva: Progress.

Ribot, T. (1901). Les maladies de la mesmoire. Paris: Ferlix Alcan.

Richardson, J.T., Zucco, G.M. (1989). Cognition and olfaction, Psychol. Bull., 105. P. 352-360.

Roelfsema, P.R., Engel, A.K., Konig, P., et al. (1997). Visuomotor integration is associated with zero time-lag synchronization among cortical areas. Nature, 385. P. 157-161.

Rolls, E.T. (1986). Neural systems involved in emotion in primates. In R. Plutchik, H. Kellerman (eds.). Emotion. Theory, Research, and Experience. Biological Foundations of Emotion, 3. New York: Academic Press, Inc. P. 125-143.

Rolls, E.T. (1999). The Brain and Emotion. Oxford: Oxford Univ. Press.

Royet, J.-P., Zald, D., Versace, et al. (2000). Emotional responses to pleasant and unpleasant olfactory, visual and auditory stimuli: a positron emission tomography study. J. Neurosci., 20. P. 7752-7759.

Rubinshtein, S.L. (1989). Osnovy obsshey psikhologii [Basics of General Psychology]. Moskva: Pedagogika.

Schachter, S. (1964). The interaction of cognitive and physiological determinants of emotional state. In L. Berkowitz (ed.). Advances in Experimental Social Psychology. New York: Academic Press. P. 49-79.

Schneirla, T.C. (1939). A theoretical consideration of the basis for approachwithdrawal adjustments in behavior. Psychol. Bull, 37. P. 501-502.

Schneirla, T.C. (1959). An evolutionary and developmental theory of biphasic processes underlying approach and withdrawal. In M.R. Jones (ed.). Neb. Symp. Motiv., 7. Lincoln: University of Nebraska Press. P. 1-42.

Schouela, D. A., Steinberg, L.M., et al. (1980). Development of the cognitive organisation of an environment. Can. J. Behav. Sci., 12. P. 1-16.

Schouten, D. (1999). Disconnecting the concepts of consciousness: the virtues of interdisciplinarity. New Ideas Psychol., 17. P. 291-308. 
Searle, J.R. (1990). Consciousness, explanatory inversion, and cognitive science. Behav. Brain Sci., 13. P. 585-642.

Searle, J.R. (1992). The Rediscovery of the Mind. Cambridge: MIT Press.

Searle, J.R. (2000). Consciousness. Annu. Rev. Neurosci., 23. P. 557-578

Singer, W. (1995). Development and plasticity of cortical processing architecture. Science, 270. P. 758-764.

Singer, T., Seymour, B., O’Doherty, J.H., et al. (2004). Empathy for pain involves the affective but not sensory components of pain. Science, 303. P.1157-1162.

Shanon, B. (2001). Against the spotlight model of consciousness. New Ideas Psychol., 19. P. 77-84.

Shima, K., Aya, K., Mushiake, H., et al. (1991). Two movement related foci in the primate cingulate cortex observed in signal-triggered and self-paced forelimb movements. J. Neurophy-siol., 65. P. 188-202.

Shoers, T.J., Miesegaes, G., Beylin, A., et al. (2001). Neurogenesis is involved in the formation of trace memories. Nature, 410. P. 372-375.

Shvyrkov, V.B. (1978; 1990). Neurophysiological Study of Systemic Mechanisms of Behavior. New Delhi: Oxonian Press.

Shvyrkov, V.B. (1986). Behavioral specializations of neurons and system-selection hypothesis of learning. In F. Klix, H. Hagendorf (eds.). Human Memory and Cognitive Capabilities. Amsterdam: Elsevier. P. 599-611.

Simonov, P.V. (1994). Soznanie: chto eto takoe? [Consciousness: what is it?]. Plenum nauchnogo soveta Mezhdunarodnogo issledovatel'skogo tsentra neyrobiologil soznaniya "Svetloe pyatno". Zhurnal vysshej nervnoj deyatelnosti, 44. P. 1158-1161.

Sneddon, L.U., Braithwaite, V.A., Gentle, M.J. (2003). Do fishes have nociceptors? Evidence for the evolution of a vertebrate sensory system. Proc. R. Soc. London, 270 P. 1115-1121.

Strongman, K.T. (1987). The Psychology of Emotion. Chichester: John Wiley and Sons.

Swadlow, H.A., Hicks, T.P. (1997). Subthreshold receptive fields and baseline excitability of "silent" S1 callosal neurons in awake rabbits: contributions of AMPA/kainate and NMDA receptors. Exp. Brain Res., 115. P. 403-409.

Tassinary, L.G., Cacioppo, J.T. (1992). Unobservable facial actions and emotion. Psychol. Sci., 3. P. 28-33.

Thatcher, R.W. (1997). Neural coherence and the content of consciousness. Conscious. Cogn., 6. P. 42-49.

Thompson, L.T., Best, P.J. (1990). Long-term stability of the place-field activity of single units recorded from the dorsal hippocampus of freely behaving rats. Brain Res., 509. P. 299-308.
Thompson, E., Varela, F.J. (2001). Radical embodiment: neural dynamics and consciousness. Trends Cogn. Sci., 5. P. 418-425.

Tiihonen, J., Kuikka, J., Hakola, P., et al. (1994). Acute ethanol-induced changes in cerebral blood flow. Am. J. Psychiatry, 151. P. 1505-1508.

Tiihonen, J., Kuikka, J., Kupila, J., et al. (1994). Increase in cerebral blood flow of right prefrontal cortex in man during orgasm. Neurosci. Lett., 170. P. 241-243.

Tikhomirov, O.K. (1975). Psihologicheskie issledovaniya tvorcheskoy deyatel'nosti [Psychological study of a creative activity]. Moskva: Nauka.

Tononi, G., Sporns, O., Edelman, G.M. (1994). A measure for brain complexity: relating functional segregation and integration in the nervous system. Proc. Natl. Acad. Sci. U. S. A., 91. P. 5033-5037.

Tononi, G., Edelman, G.M. (1998). Consciousness and complexity. Science, 282. P. 1846-1851.

Trewavas, A. (2003). Aspects of plant intelligence. Ann. Bot., 92. P. 1-20.

Tulving, E. (1985). Memory and consciousness. Can. Psychol., 26. P. 1-12.

Uexkull, J. Von (1957). A stroll through the worlds of animals and men. Instinctive Behavior. New York: Int. Univ. Press. P. 5-80.

Van der Veer, R. (1996). Henri Wallon's theory of early child development: the role of emotions. Dev. Rev., 16. P. 364-390.

Vandervert, L.R. (1995). Chaos theory and the evolution of consciousness and mind: a thermodynamic-holographic resolution to the mind- body problem. New Ideas Psychol., 13. P. 107-127.

Vandervert, L.R. (1998). Consciousness: a preliminary multidiscipli-nary mapping of concepts. New Ideas Psychol., 16. P. 159-164.

Vanderwolf, C.H. (1998). Brain, behavior, and mind: what do we know and what can we know? Neurosci. Biobehav. Rev., 22. P. 125-142.

Vanderwolf, C.H., Kelly, M.E., et al. (1988). Are emotion and motivation localized in the limbic system and nucleus accum-bens? Behav. Brain Res., 27. P. 45-58.

Vygotsky, L.S. (1982). Sobranie sochinenij, tom 1 [Collection of Scientific Works, vol. 1]. Moskva: Pedagogika.

Werner, H. (1948). Comparative psychology of mental development. New York: Science Edition.

Werner, H., Kaplan, B. (1956). The developmental approach to cognition: its relevance to the psychological interpretation of anthropological and ethnolinguistic data. Am. Anthropol., 58. P. 866-880.

Whalen, P.J., Rauch, S.L., Etcoff, et al. (1998). Masked presentations of emotional facial expressions modulate amygdala activity without explicit knowledge. J. Neurosci., 18. P. $411-418$ 
Whitehead, H. (1998). Cultural selection and genetic diversity in matrilineal whales. Science, 282. P. 1708-1711.

Whiten, A., Goodall, J., McGrew, W.C., et al. (1999). Cultures in chimpanzees. Nature, 399. P. 682-685.

Wilson, E.O. (1998). Consilience: The Unity of Knowledge. New York: A. Knoff.

Wilson, M.A., McNaughton, B.L. (1993). Dynamics of the hippocampal ensemble code for space. Science, 261. P. 1055-1058.

Woodward, D.J. Janak, P.H. Chang, J.-Yu. (1998). Ethanol action on neuronal networks studied with multineuron recording in freely moving animals. Alcohol.: Clin. Exp. Res., 22. P. 10-22.

Yamamoto, T., Matsuo, R., et al. (1989). Response properties of lateral hypothalamic neurons during ingestive behavior with special reference to licking of various taste solutions. Brain Res., 481. P. 286-297.

Zajonc, R.B. (1980). Feeling and thinking. Preferences need no inferences. Am. Psychol., 35. P. 151-175.

Zajonc, R.B., McIntosh, D.N. (1992). Emotions research: some promising questions and some questionable promises. Psychol. Sci., 3. P. 70-74.

Zeki, S. (2003). The disunity of consciousness. Trends Cogn. Sci., 7. P. 214-218.

Zelazo, P.D. (2004). The development of conscious control in childhood. Trends Cogn. Sci., 8. P. 12-17. 